University of Nebraska - Lincoln

DigitalCommons@University of Nebraska - Lincoln

Faculty Publications from the Harold W. Manter Laboratory of Parasitology

2005

\title{
Molecular Phylogenetics and Diagnosis of Anisakis, Pseudoterranova, and Contracaecum from Northern Pacific Marine Mammals
}

\author{
Steven A. Nadler \\ University of California - Davis, sanadler@ucdavis.edu \\ Stefano D'Amelio \\ University of Rome "La Sapienza" \\ Murray D. Dailey \\ Marine Mammal Center \\ Lia Paggi \\ University of Rome "La Sapienza" \\ Sandra Siu \\ University of California - Davis \\ See next page for additional authors \\ Follow this and additional works at: https://digitalcommons.unl.edu/parasitologyfacpubs \\ Part of the Parasitology Commons
}

Nadler, Steven A.; D'Amelio, Stefano; Dailey, Murray D.; Paggi, Lia; Siu, Sandra; and Sakanari, Jusy A., "Molecular Phylogenetics and Diagnosis of Anisakis, Pseudoterranova, and Contracaecum from Northern Pacific Marine Mammals" (2005). Faculty Publications from the Harold W. Manter Laboratory of Parasitology. 740.

https://digitalcommons.unl.edu/parasitologyfacpubs/740

This Article is brought to you for free and open access by the Parasitology, Harold W. Manter Laboratory of at DigitalCommons@University of Nebraska - Lincoln. It has been accepted for inclusion in Faculty Publications from the Harold W. Manter Laboratory of Parasitology by an authorized administrator of DigitalCommons@University of Nebraska - Lincoln. 


\section{Authors}

Steven A. Nadler, Stefano D'Amelio, Murray D. Dailey, Lia Paggi, Sandra Siu, and Jusy A. Sakanari 


\title{
MOLECULAR PHYLOGENETICS AND DIAGNOSIS OF ANISAKIS, PSEUDOTERRANOVA, AND CONTRACAECUM FROM NORTHERN PACIFIC MARINE MAMMALS
}

\author{
Steven A. Nadler, Stefano D’Amelio*, Murray D. Dailey†, Lia Paggi`, Sandra Siu, and Judy A. Sakanarił \\ Department of Nematology, University of California, Davis, California 95616-8668. e-mail: sanadler@ucdavis.edu
}

\begin{abstract}
Individual specimens of Anisakis, Pseudoterranova, and Contracaecum collected from marine mammals inhabiting northern Pacific waters were used for comparative diagnostic and molecular phylogenetic analyses. Forty-eight new sequences were obtained for this study of 14 Anisakis taxa, 8 Pseudoterranova taxa, 4 Contracaecum taxa, and 4 outgroup species. Partial $28 \mathrm{~S}$ (LSU) and complete internal transcribed spacer (ITS-1, 5.8S, ITS-2) ribosomal DNA was amplified by the polymerase chain reaction and sequenced. Sequences of ITS indicated that Pseudoterranova specimens from Zalophus californianus (California sea lion), Mirounga angustirostris (northern elephant seal), Phoca vitulina (harbor seal), Enhydra lutris (sea otter), and Eumetopias jubatus (Steller's sea lion) exactly matched P. decipiens s. str., extending the host and geographic range of this species. Anisakis from northern Pacific marine mammals were most closely related to members of the A. simplex species complex. Comparison of Anisakis ITS sequences diagnosed the presence of A. simplex $\mathrm{C}$ in $2 \mathrm{M}$. angustirostris hosts, which is a new host record. Anisakis specimens from Phocoena phocoena (harbor porpoise), Lissodelphis borealis (Pacific rightwhale porpoise), and E. jubatus included 3 ITS sequences that did not match any known species. Contracaecum adults obtained from Z. californianus were most closely related to $C$. ogmorhini s.l. and $C$. rudolphii, but ITS sequences of these Contracaecum specimens did not match C. ogmorhini s. str. or C. margolisi. These novel Anisakis and Contracaecum ITS sequences may represent previously uncharacterized species. Phylogenetic analysis of LSU sequences revealed strong support for the monophyly of Anisakinae, Contracaecum plus Phocascaris, Pseudoterranova, and Anisakis. Phylogenetic trees inferred from ITS sequences yielded robustly supported relationships for Pseudoterranova and Anisakis species that are primarily consistent with previously published phenograms based on multilocus electrophoretic data.
\end{abstract}

Anisakid nematodes are common parasites of marine mammals, and have a worldwide distribution. Larvae of these nematodes are a major problem for commercial fishing industries (Rohlwing et al., 1998), and are potential human health hazards, both as causative agents of anisakiasis (Sakanari and McKerrow, 1989), and as potential food-borne allergens (Moneo et al., 2000; Baeza et al., 2001). Numerous studies employing data from multilocus enzyme electrophoresis have revealed that morphospecies of Anisakis, Contracaecum, and Pseudoterranova consist of genetically differentiated sibling species with different geographic and host distributions (Mattiucci et al., 1986; Nascetti et al., 1986; Orecchia et al., 1986; Paggi et al., 1991; Nascetti et al., 1993; Mattiucci et al., 1997, 1998; Paggi, Mattiucci et al., 1998; Paggi et al., 2000; Mattiucci et al., 2003). These population-level allozyme studies have been instrumental in detecting evidence of genetic heterogeneity (noninterbreeding individuals within populations) among large samples of ascaridoids collected from paratenic or definitive hosts in nature (Paggi and Bullini, 1994; Bullini et al., 1997), and have led to the discovery and description of several new species. Such studies have facilitated the development of other molecular diagnostic tools for these species, in particular, those based on the polymerase chain reaction (PCR) including PCR-restriction fragment length polymorphism (PCR-RFLP) (Zhu, Gasser, Podolska, and Chilton, 1998; D'Amelio et al., 2000; Kijewska et al., 2002; Shih, 2004), single-strand conformational polymorphism (SSCP) of PCR products (Zhu, Gasser, Podolska, and Chilton, 1998; Zhu et al., 2000; Hu et al., 2001; Zhu et al., 2001, 2002), and direct sequencing of PCR-amplified DNA

Received 19 November 2004; revised 21 March 2005; accepted 21 March 2005.

* Section of Parasitology, Department of Public Health Sciences, University of Rome "La Sapienza," Piazzale Aldo Moro, 5, I-00185 Rome, Italy.

$\dagger$ The Marine Mammal Center, Marin Headlands, 1065 Fort Cronkhite, Sausalito, California 94965.

$\ddagger$ Department of Biology, Sonoma State University, 1801 E. Cotati Avenue, Rohnert Park, California 94928.
(Zhu, Gasser, Podolska, and Chilton, 1998; Nadler et al., 2000; Zhu et al., 2000; Hu et al., 2001; Zhu et al., 2001, 2002; Mattiucci et al., 2003). These DNA-based diagnostic techniques are advantageous because individual alcohol-preserved adults and larvae can be identified; in contrast, allozyme techniques require enzymatic activities that are only preserved in frozen tissues. Diagnostic DNA markers from a single genetic locus can be quite useful for nematode identification (Gasser et al., 1996; Zhu, Gasser, Podolska, and Chilton, 1998; D'Amelio et al., 2000; Nadler et al., 2003). However, such single-locus studies are of considerably less utility for finding and delimiting new species in nature (Nadler, 2002, 2005). Nevertheless, unexpected nucleotide sequence variation at even 1 locus provides valuable information that can lead to testing hypotheses of species using multilocus datasets (allozymes or DNA based approaches) with reference to explicit species concepts (Adams, 1998; Nadler, 2002).

The most detailed studies of North American marine mammal ascaridoids have focused on hosts from Canadian Atlantic waters (Brattey and Ni, 1992; Brattey and Stenson, 1993; Brattey and Davidson, 1996). These investigations have characterized ascaridoids in Halichoerus grypus (gray seal, GS), Phoca vitulina (harbor seal, HS), Phoca hispida (ringed seal, RS), Cystophora cristata (hooded seal, HDS), Phoca groenlandica (harp seal, HRS), and Erignathus barbatus (bearded seal, BS), and have used molecular methods to identify species of Anisakis, Pseudoterranova, Contracaecum, Phocascaris, when assessing parasite abundance and host distribution. Studies using molecular tools to diagnose ascaridoids in North American Pacific waters have been very limited in scope. For Anisakis, investigators have used allozyme and PCR-RFLP techniques to document adults of $A$. simplex C (Mattiucci et al., 1997; D'Amelio et al., 2000) from Pseudorca crassidens (false killer whale) and A. simplex s. str. from Phocoena phocoena (harbor porpoise, HP) and P. crassidens (Mattiucci et al., 1997; D' Amelio et al., 2000) occurring in Canadian Pacific waters. Contracaecum ogmorhini s.l. was reported from Zalophus californianus (Cali- 
fornia sea lion, CSL) in Mexican and Californian Pacific waters (Fagerholm and Gibson, 1987), and these authors predicted this parasite would be found in additional host species from the Pacific, including Callorhinus ursinus (northern fur seal, NFS) and Eumetopias jubatus (Steller's sea lion, SSL). More recent genetic studies show that $C$. ogmorhini s.l. consists of 2 sibling species, C. ogmorhini s. str. and Contracaecum margolisi (Mattiucci et al., 2003), with the latter species diagnosed genetically (Zhu et al., 2001; Mattiucci et al., 2003) from 1 locality (Vancouver Island, Canada) in Z. californianus (CSL). The third common genus of marine mammal ascaridoid, Pseudoterrano$v a$, is also a complex of at least 5 species (Paggi et al., 1991; Mattiucci et al., 1998; George-Nascimento and Urrutia, 2000; Paggi et al., 2000; Zhu et al., 2002) that can be diagnosed by allozyme markers (Paggi et al., 2000), nucleotide sequences (Zhu et al., 2002), and, for adult males, morphometric differences (Di Deco et al., 1994; Mattiucci et al., 1998; GeorgeNascimento and Urrutia, 2000; Paggi et al., 2000). Reports of Pseudoterranova decipiens from North American Pacific waters predate the common use of molecular markers to identify species, thus, Pseudoterranova taxa from these hosts have not yet been investigated relative to recently described species.

In the present study, specimens of Anisakis, Pseudoterrano$v a$, and Contracaecum collected from marine mammals inhabiting North American Pacific waters were sequenced for ITS ribosomal DNA (rDNA), compared with diagnostic sequences for known species, and used to infer phylogenies. Some of these specimens were also sequenced for a region of LSU rDNA and analyzed in a comparative phylogenetic context to assess relationships among taxonomic groups of aquatic ascaridoids.

\section{MATERIALS AND METHODS}

\section{Taxa for molecular systematics}

Nematodes (Table I) were obtained from stranded marine mammals by staff at the Marine Mammal Center, Sausalito, California. Ascaridoids were collected at necropsy, preserved in $95 \%$ ethanol, and stored at $-20 \mathrm{C}$. Anterior and posterior ends of specimens were removed, cleared in lactophenol, and diagnosed by microscopy. Morphologically, the northern Pacific specimens corresponded to A. simplex s.1., P. decipiens s.1., or C. ogmorhini s.1. Four of the other Anisakis specimens used for comparative study were diagnosed to species based on morphology (A. typica, A. ziphidarum, A. physeteris, and A. brevispiculata), and all such reference species were confirmed by using diagnostic allozyme markers. Voucher specimens of northern Pacific specimens have been retained in the University of California-Davis frozen tissue collection. Contracaecum and Pseudoterranova reference ITS sequences were obtained from GenBank as were 34 of 56 partial LSU sequences used for phylogenetic analysis (Table I). Additional ascaridoids sequenced for comparative analysis of LSU rDNA included Parascaris equorum, Ascaris suum, Baylisascaris procyonis, Hysterothylacium auctum, and Raphidascaris acus (Table I).

\section{DNA amplification and sequencing}

DNA was extracted from pieces of individual nematodes using commercial kits (DNAzol, Molecular Research Center Inc., Cincinnati, Ohio; MasterPure ${ }^{\mathbb{T N}}$, Epicentre Technologies, Madison, Wisconsin). A region of the $5^{\prime}$ end of the nuclear large subunit ribosomal RNA gene (LSU rDNA) containing the D2 and D3 divergent domains was amplified using a forward PCR primer (\#391, 5'-AGCGGAGGAAAAGAA ACTAA, or \#538, 5'-AGCATATCATTTAGCGGAGG) in combination with a reverse primer (\#390, 5'-ATCCGTGTTTCAAGACGGG, or \#501, 5'-TCGGAAGGAACCAGCTACTA). A region of nuclear rDNA including the internal transcribed spacers (ITS-1, ITS-2) and 5.8S subunit was amplified using primers that anneal to the $3^{\prime}$ end of the $18 \mathrm{~S}$
rDNA (\#93, 5'-TTGAACCGGGTAAAAGTCG) and the 5' end of the 28S rDNA (\#94, 5'-TTAGTTTCTTTTCCTCCGCT). PCR reactions (25 $\mu 1)$ consisted of $0.5 \mu \mathrm{M}$ each primer, $200 \mu \mathrm{M}$ deoxynucleoside triphosphates, and $\mathrm{MgCl}_{2}$, ranging from 1.5 to $3 \mathrm{mM}$ as required for specific amplification. Proofreading polymerase (0.5 unit, Finnzymes DNAzyme EXT, MJ Research, Waltham, Massachusetts) was used for $\mathrm{PCR}$, and cycling parameters included denaturation at $94 \mathrm{C}$ for $3 \mathrm{~min}$, followed by 35 cycles of $94 \mathrm{C}$ for $30 \mathrm{sec}, 48-57 \mathrm{C}$ for $30 \mathrm{sec}$, and 72 $\mathrm{C}$ for $1 \mathrm{~min}$, followed by a postamplification extension at $72 \mathrm{C}$ for 7 min. PCR products were prepared for direct nucleotide sequencing by using enzymatic treatment with exonuclease I and shrimp alkaline phosphatase (PCR product presequencing kit, USB Corporation, Cleveland, Ohio). PCR products were cloned when they could not be successfully sequenced directly. For cloning, PCR products were washed 3 times with TE buffer ( $\mathrm{pH}$ 7.0) by spin filtration (Millipore Ultrafree-MC 30,000 NMWL, Millipore Corporation, Bedford, Massachusetts), ligated into pGEM-T vector (Promega, Madison, Wisconsin), and cloned into JM109 Escherichia coli. Plasmid DNA was obtained using Qiaprep spin miniprep kits (Qiagen, Valencia, California). Sequencing reactions were performed using dye-terminator sequencing chemistry, and reaction products were separated and detected using an ABI 3730 capillary DNA sequencer (PE Applied Biosystems, Boston, Massachusetts). All sequences were completely double stranded for verification using reactions primed from the PCR or vector primers and 2 or more internal sequencing primers. Site polymorphisms in directly sequenced PCR products were recorded only when both alternative nucleotide peaks were present in all sequence reactions representing both DNA strands. If the heights of the alternative nucleotide peaks at polymorphic sites were not equal, the height of the minor peak was required to significantly exceed background terminations and comprise at least $25 \%$ of the major peak to be scored as a polymorphism (Nadler et al., 2003). For cloned rDNA, conflicts between clones were recorded as polymorphisms. Phred base-calling was used before contig assembly with CodonCode Aligner (Version 1.2.2).

\section{Phylogenetic analyses}

Sequences determined in this study (indicated in Table I), plus those obtained from GenBank, were aligned using ProAlign Version 0.5 (Löytynoja and Milinkovitch, 2003). For each alignment, a ProAlign guide tree was constructed using corrected (for multiple hits) pairwise distances; this guide tree was used to estimate the hidden Markov model parameters $(\delta$ and $\epsilon$ ) for progressive multiple alignment. Program (Java) memory and band widths were increased, as required, to complete the alignment. The minimum posterior probability of sites was used as the criterion for detecting and removing unreliably aligned sequence. To reduce the likelihood of excluding correctly aligned sites, the filter threshold was set to $60 \%$ minimum posterior probability (Löytynoja and Milinkovitch, 2003). Pairwise sequence differences (absolute distances) were determined from multiple alignments using PAUP* 4.0b10 (Swofford, 1998). Phylogenetic trees were inferred using unweighted maximum parsimony (MP) and maximum likelihood (ML) methods using PAUP* executed on a dual-processor Linux computer. Gaps were treated as missing data in parsimony analyses. Modeltest Version 3.06 (Posada and Crandall, 1998) was used to compare the fit of nucleotide substitution models for datasets using the Akaike information criterion. The best-fit ML model for each dataset was used for likelihood analysis.

For the 56-taxa LSU dataset, heuristic MP searches were conducted using 500 replicates of random taxon addition with tree-bisection-reconnection (TBR) branch swapping. Bootstrap MP searches were conducted using 1,000 pseudoreplicates, with random taxon addition and a search time limit of $30 \mathrm{sec}$ per pseudoreplicate. Maximum likelihood trees were inferred using a neighbor-joining (NJ) starting tree, with heuristic searching of tree space by TBR branch swapping. The bootstrap ML tree was produced using 100 pseudoreplicates of heuristic searches as indicated for individual ML trees, except each replicate was limited to $800 \mathrm{sec}$. Maximum parsimony and ML trees were rooted using Heterocheilus tunicatus (Ascaridoidea, Heterocheilidae), a choice supported by previous analyses of molecular datasets (Nadler and Hudspeth, 1998, 2000).

For the Anisakis and Pseudoterranova ITS datasets, MP searches were conducted using the branch-and-bound method; bootstrap MP trees were inferred using 1,000 pseudoreplicates of branch-and-bound. Maximum likelihood and bootstrap ITS ML trees were inferred using 
the same methods as for the LSU dataset. The sister-group relationship of Anisakis and Pseudoterranova recovered in analysis of ribosomal DNA and mitochondrial sequences (Nadler and Hudspeth, 1998, 2000) and for regions of LSU sequence (this study) was the basis for using Anisakis to root the Pseudoterranova ITS tree, and in a separate analysis, Pseudoterranova to root the Anisakis ITS tree. Thus, these ITS analyses cannot be used to test the monophyly of Pseudoterranova or Anisakis. Phylogenetic analyses that would permit more comprehensive comparisons and tests of monophyly with ITS sequences through inclusion of more "basal" ascaridoid taxa were not undertaken because of substantial regions of positional homology uncertainty in ITS alignments that included more taxonomically diverse ascaridoids.

\section{RESULTS}

\section{$28 \mathrm{~S}$ rDNA sequence data and analysis}

Sequences of LSU rDNA from 9 Pseudoterranova specimens (8 P. decipiens s.l. and 1 P. decipiens s. str.) were identical. These included individual nematodes obtained from $2 P$. vitulina (HS), 3 Z. californianus (CSL), 1 Mirounga angustirostris (northern elephant seal, NES), 1 Enhydra lutris (sea otter, SO), and 1 E. jubatus (SSL). These sequences also matched the LSU sequence of $P$. decipiens s. str. (Nadler and Hudspeth, 1998). Likewise, LSU sequences of 4 Contracaecum specimens obtained from $4 \mathrm{Z}$. californianus (CSL) were identical and matched the sequence of $C$. ogmorhini s. str. (Nadler et al., 2000) obtained from Arctocephalus pusillus pusillus (Cape fur seal, CFS). Pairwise comparisons of Anisakis LSU sequences showed absolute nucleotide distances ranging from 0 to 5 differences. All 3 Anisakis individuals from $M$. angustirostris (NES) hosts were identical in sequence, as were specimens from 1 E. jubatus (SSL) and 1 Lissodelphis borealis (Pacific rightwhale porpoise, PRP).

For phylogenetic analysis of LSU sequences, using ProAlign to detect and remove unreliably aligned sites by their posterior probabilities excluded 52 of 712 alignment sites. This dataset of 660 characters included 206 parsimony informative sites. Maximum parsimony analysis of the LSU dataset yielded 4 most parsimonious trees of 774 steps (C.I. $=0.53$ ). The strict consensus of these trees (Fig. 1) depicted Anisakis plus (Pseudoterranova, Terranova) as monophyletic, with $100 \%$ bootstrap support. Likewise, representatives of Pseudoterranova and Anisakis were each monophyletic, with $100 \%$ and $93 \%$ bootstrap support, respectively. The strict consensus of MP trees also revealed a monophyletic Contracaecum plus Phocascaris clade, with $100 \%$ bootstrap support. Anisakidae (sampled genera included Anisakis, Pseudoterranova, Contracaecum, Phocascaris) was not a clade in the strict consensus of MP trees or in the bootstrap majority-rule MP consensus tree. Genera in the Raphidascarididae (Hysterothylacium, Goezia, Iheringascaris, and Raphidascaris) were monophyletic in the MP trees, but this clade received low bootstrap support (69\%). Taxa from the Ascaridinae (Parascaris, Ascaris, Toxascaris, Baylisascaris) were strongly supported as monophyletic (99\% bootstrap), but Ascarididae was not monophyletic because of the exclusion of Toxocara. In general, relationships among these clades, e.g., Raphidascaridae, Ascaridinae, and Anisakinae, representing the deepest nodes in the phylogenetic hypothesis, were not reliably supported as assessed by MP bootstrap resampling (Fig. 1).

Maximum likelihood analysis of the 660-character LSU dataset yielded a single tree (Fig. 2). Anisakis plus (Pseudoterranova, Terranova) was monophyletic in the ML tree with
$100 \%$ bootstrap support. Like for MP trees, Pseudoterranova, Anisakis, and Contracaecum + Phocascaris were each monophyletic, with $\geq 99 \%$ support in ML bootstrap trees. Unlike the MP result, the ML tree recovered a monophyletic Anisakidae, but this clade was not found in the ML bootstrap majority-rule consensus tree. The Raphidascarididae received moderate $(89 \%)$ support in the ML bootstrap tree. Genera representing Ascaridinae were strongly supported as monophyletic (100\% bootstrap), but representatives of the Toxocarinae (Toxocara, Porrocaecum) were more closely related to anisakids (Toxocara) or the clade that included anisakids plus raphidascarids in the ML tree. As found for bootstrap MP analysis, the deepest nodes in the phylogenetic tree were not reliably supported as assessed by bootstrap resampling with ML inference (Fig. 2).

\section{ITS rDNA sequence data and analysis}

Sequences of ITS rDNA from 7 of the 8 Pseudoterranova specimens from Pacific waters (obtained from 5 different host species, Table I), were identical and matched the sequence of P. decipiens s. str. (Zhu et al., 2002). One Pseudoterranova sequence from a Z. californianus (CSL) host (CSL, 4994) was polymorphic (A/G) at 1 ITS-2 site (position 50 in the alignment of Zhu et al., 2002) that was an adenine in the other CSL Pseudoterranova specimens. This polymorphic nucleotide occurred at the single site that distinguishes the ITS sequences of $P$. decipiens s. str. (adenine at this site) from Pseudoterranova azarasi (guanine at this site).

Sequences of ITS rDNA from the 4 Contracaecum specimens obtained from $4 Z$. californianus (CSL) hosts were identical except for 1 ITS-1 polymorphism in 1 individual (CSL, 4836). These sequences were not identical with any of the $C$. ogmorhini s.l. published sequences (Zhu et al., 2001), which are highly conserved, with only 1 ITS-1 site and 2 ITS-2 site differences (Fig. 3) between austral (C. ogmorhini s. str.) and boreal (C. margolisi) species. Three of 4 Contracaecum individuals sequenced from $Z$. californianus hosts in this study matched the sequence of $C$. margolisi (from a Pacific Canada Z. californianus) at all 3 sites (1 ITS-1, 2 ITS-2) that distinguish C. ogmorhini s. str. from C. margolisi, including the diagnostic ITS-2 BstN1 restriction site (Zhu et al., 2001). The polymorphic $(\mathrm{C} / \mathrm{T})$ ITS-1 site found in 1 individual (Fig. 1, position 254) occurred at a site that distinguishes $C$. ogmorhini s. str. (cytosine at this site) from $C$. margolisi (thymine at this site). All 4 of the Contracaecum sequences from $Z$. californianus hosts had 1 ITS-1 difference (position 407, a transition) that distinguished them from $C$. ogmorhini s. str. and C. margolisi. Three additional ITS-1 sequence sites were different for published $C$. ogmorhini s.1. sequences (Zhu et al., 2001) and the 4 Contracaecum sequences from $Z$. californianus hosts obtained from California. The characteristics of these differences are consistent with potential errors in the previously published sequences. For example, GA dinucleotides at positions 91-92 are AG in the newly obtained sequences (Fig. 3) and also in 6 Contracaecum osculatum sequences (Zhu et al., 2000). Similarly, there are 2 C nucleotides at positions 240-241 (trailing $\mathrm{C}$ also in $6 C$. osculatum sequences) and $2 \mathrm{~T}$ nucleotides at positions 409-410 rather than the single nucleotide indicated in each case for previously published sequences (Zhu et al., 2001).

Pairwise comparisons of 14 Anisakis ITS sequences showed 


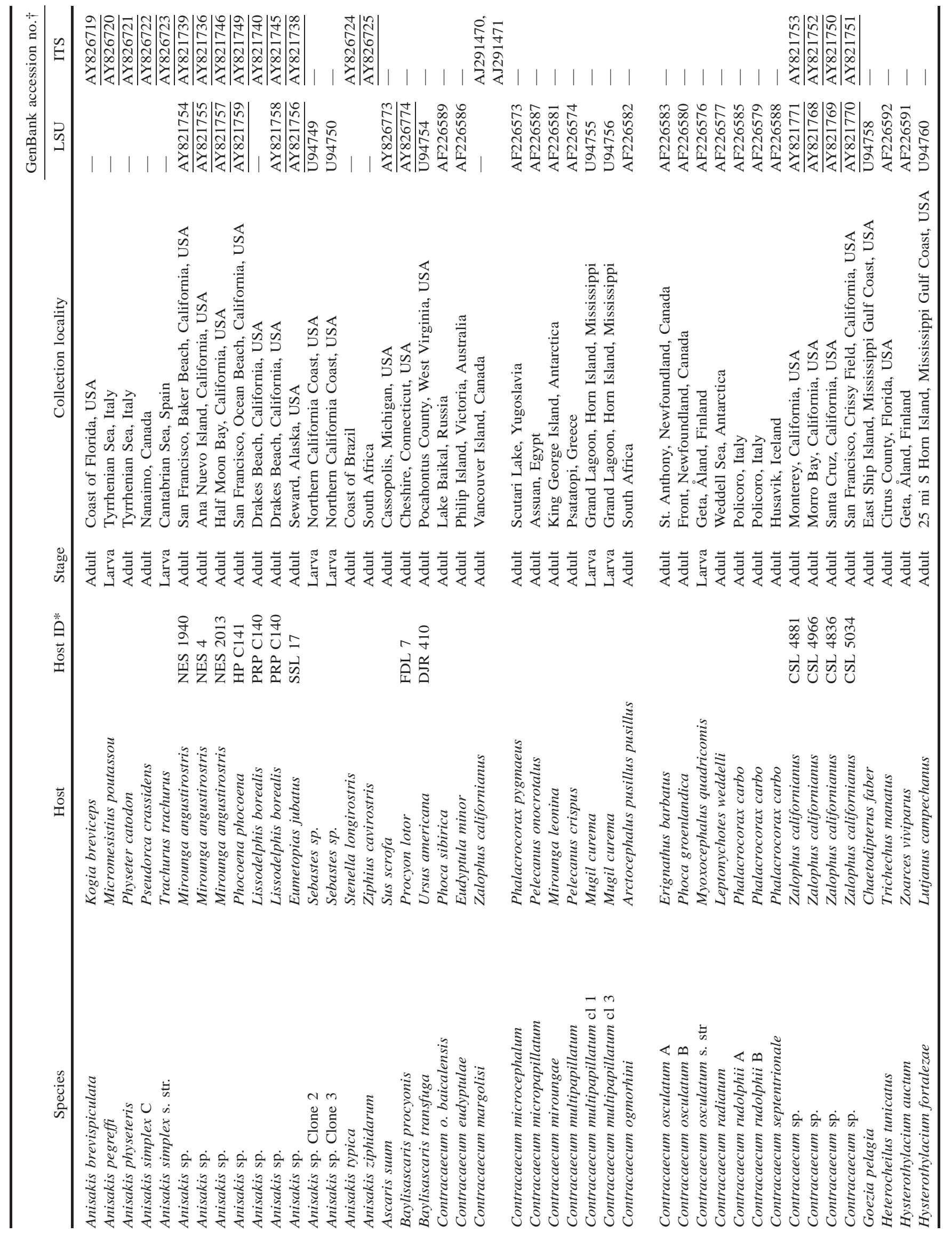




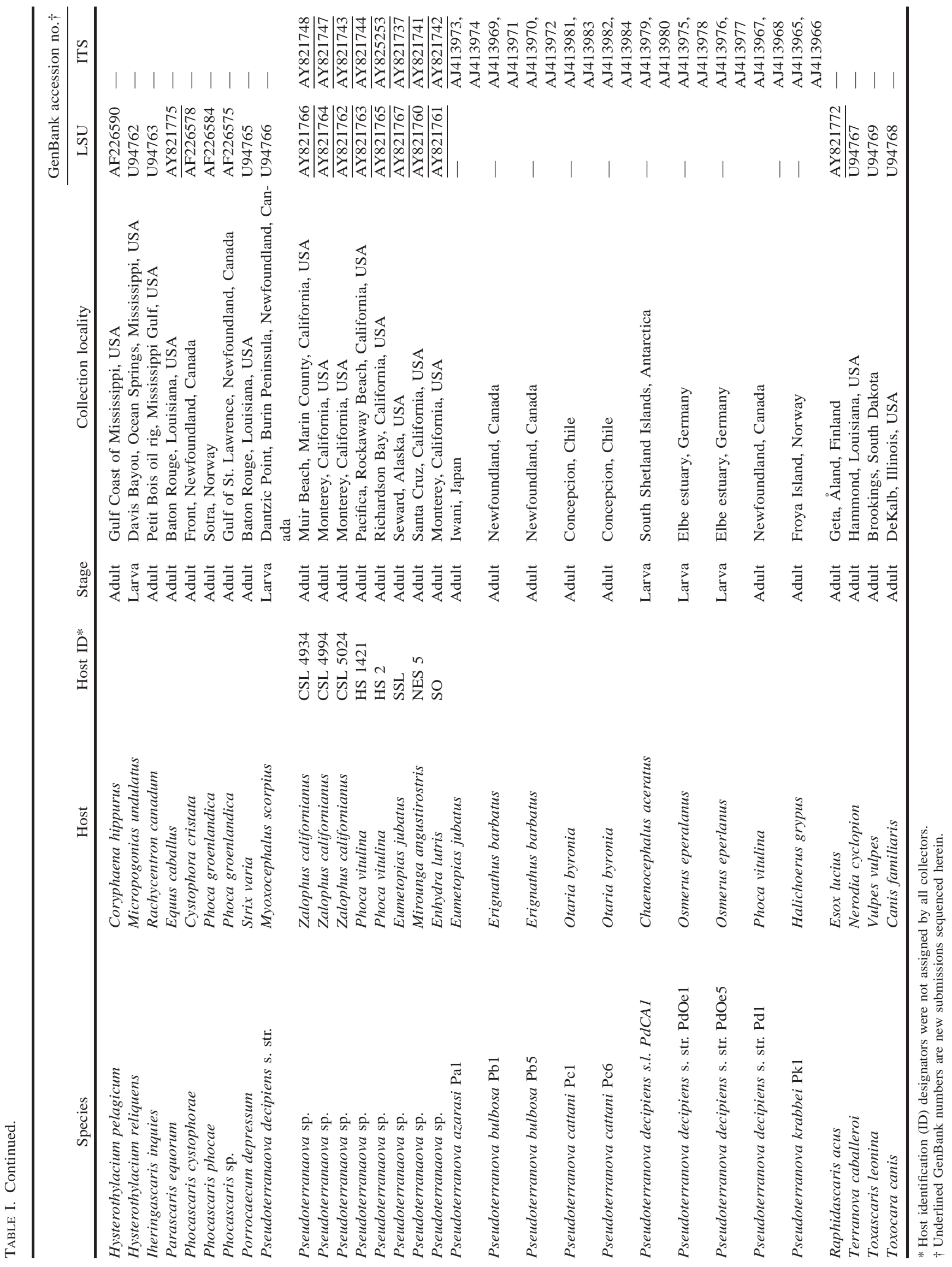




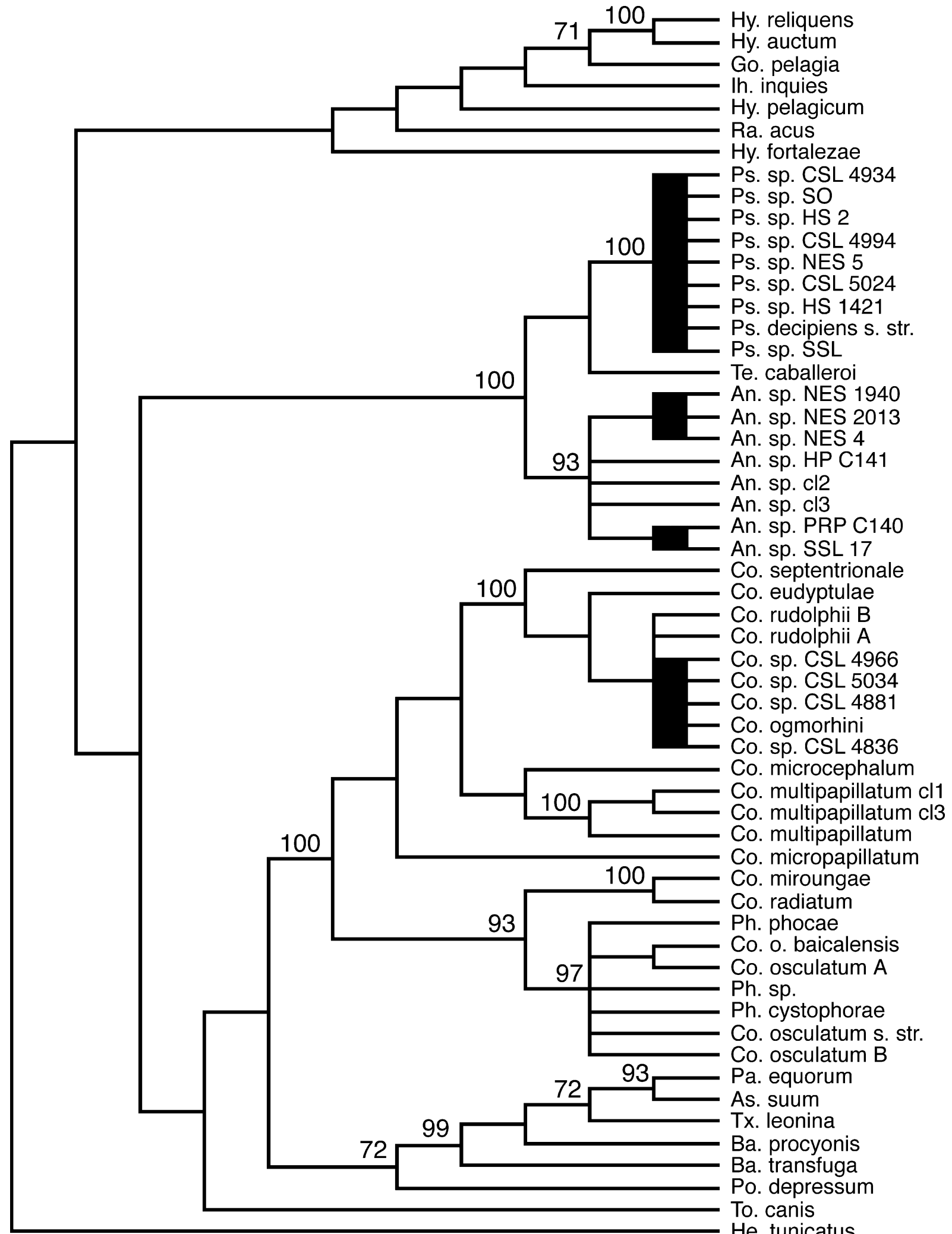

FIGURE 1. Strict consensus of 4 equally parsimonious trees inferred from LSU rDNA sequences. Trees inferred using unweighted MP from a ProAlign alignment after excluding sites with minimum posterior probabilities of $60 \%$ or less (52 of 712 sites). These 4 MP trees required 774 steps and had a C.I. of 0.53. Bootstrap percentages of clades $(\geq 70 \%)$ as inferred by MP are shown above internal nodes. Vertical black bars mark Anisakis, Contracaecum, and Pseudoterranova taxa with identical LSU sequences as inferred from pairwise comparison of the alignment without exclusion of sites. Tree rooted by Heterocheilus tunicatus outgroup. Abbreviations for genera: An (Anisakis), As (Ascaris), Ba (Baylisascaris), Co (Contracaecum), Go (Goezia), Hy (Hysterothylacium), Ih (Iheringascaris), Pa (Parascaris), Ph (Phocascaris), Po (Porrocaecum), Ps (Pseudoterranova), Ra (Raphidascaris), Te (Terranova), To (Toxocara), Tx (Toxascaris). Abbreviations for host species and individual host identifier follow selected parasite species: CSL (California sea lion), HP (harbor porpoise), HS (harbor seal), NES (northern elephant seal), PRP (Pacific rightwhale porpoise), SO (sea otter), SSL (Steller's sea lion). 


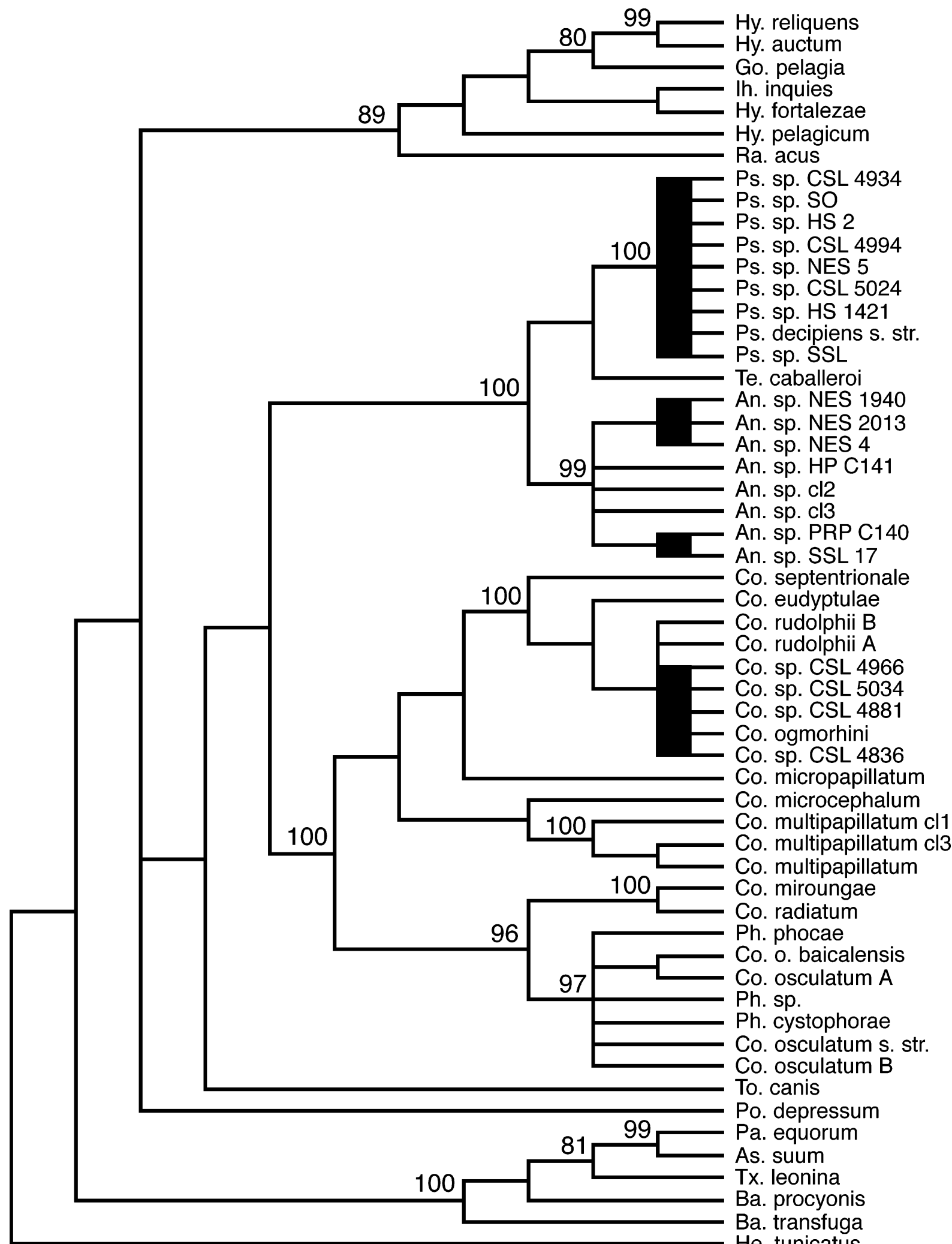

FIgURE 2. Maximum likelihood tree inferred from LSU rDNA sequences. Tree inferred from a ProAlign alignment after excluding sites with minimum posterior probabilities of $60 \%$ or less (52 of 712 sites). Vertical black bars mark Anisakis, Contracaecum, and Pseudoterranova taxa with identical LSU sequences as inferred from pairwise comparison of the alignment without exclusion of sites. Bootstrap percentages of clades $(\geq 70 \%)$ as inferred by ML are shown above internal nodes. Likelihood search conducted using TVM $+\mathrm{I}+\mathrm{G}$ model with gamma shape $=0.7169$ and Pinvar $=0.3443$ as selected by ModelTest. Tree rooted by Heterocheilus tunicatus outgroup. Abbreviations for genera: An (Anisakis), As (Ascaris), Ba (Baylisascaris), Co (Contracaecum), Go (Goezia), Hy (Hysterothylacium), Ih (Iheringascaris), Pa (Parascaris), Ph (Phocascaris), Po (Porrocaecum), Ps (Pseudoterranova), Ra (Raphidascaris), Te (Terranova), To (Toxocara), Tx (Toxascaris). Abbreviations for host species and individual host identifier follow selected parasite species: CSL (California sea lion), HP (harbor porpoise), HS (harbor seal), NES (northern elephant seal), PRP (Pacific rightwhale porpoise), SO (sea otter), SSL (Steller's sea lion). 
C. ogmorhinis. str. APD C. ogmorhini s. str. APP C. margolisi

Contracaecum sp. CSL 4966 Contracaecum sp. CSL 4836

C. ogmorhini s. str. APD c. ogmorhini s. str. APP c. margolisi

Contracaecum CSL 4966

Contracaecum sp. CSL 4836

c. ogmorhini s. str. APD c. ogmorhini s. str. APP c. margolisi

Contracaecum sp. CSL 4966 Contracaecum sp. CSL 4836

c. ogmorhini s. str. APD c. ogmorhini s. str. APP C. margolisi

Contracaecum sp. CSL 4966 Contracaecum sp. CSL 4966
Contracaecum sp. CSL 4836

c. ogmorhini s. str. APD c. ogmorhini s. str. APP c. margolisi

Contracaecum sp. CSL 4966 Contracaecum sp. CSL 4836

C. ogmorhini s. str. APD c. ogmorhini s. str. APP C. ogmorhini

Contracaecum sp. CSL 4966 Contracaecum sp. CSL 4966
Contracaecum sp. CSL 4836

C. ogmorhini s. str. APD C. ogmorhini s. str. APP C. margolisi

Contracaecum sp. CSL 4966 Contracaecum sp. CSL 4836

c. ogmorhini s. str. APD c. ogmorhini s. str. APP c. margolisi

Contracaecum sp. CSL 4966 Contracaecum sp. CSL 4836

c. ogmorhini s. str. APD c. ogmorhini s. str. APP C. margolisi

Contracaecum sp. CSL 4966 Contracaecum sp. CSL 4966
Contracaecum sp. CSL 4836

C. ogmorhini s. str. APD c. ogmorhini s. str. APP c. margolisi

Contracaecum sp. CSL 4966 Contracaecum sp. CSL 4966
Contracaecum sp. CSL 4836

c. ogmorhini s. str. APD c. ogmorhini s. str. APP C. margolisi

Contracaecum sp. CSL 4966 Contracaecum sp. CSL 4836

C. ogmorhini s. str. APD c. ogmorhini s. str. APP C. margolisi

C. margolisi Contracaecum sp. CSL 4966
Contracaecum sp. CSL 4836

C. ogmorhini s. str. APD C. ogmorhini s. str. APP c. margolisi

Contracaecum sp. CSL 4966 Contracaecum sp. CSI
10

30

40

60

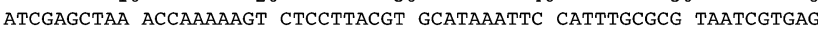

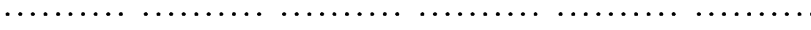

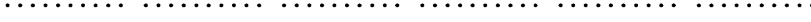

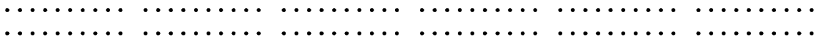

$\begin{array}{cccccc}70 & 80 & 90 & 100 & 110 & 120 \\ \text { CCATGCAGCG } & \text { AGTCATACAC } & \text { ATGTGGTGGC } & \text { GACCGTCGGC } & \text { TGTTTTTCRT } & \text { TTTGGCTGACA }\end{array}$

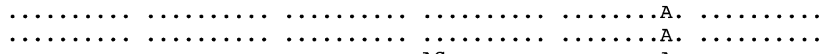

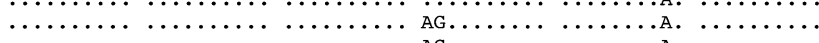

$130 \quad 150 \quad 160$

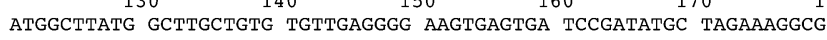

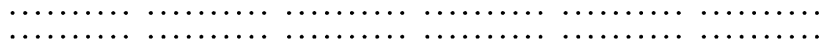

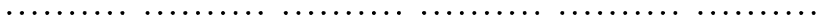

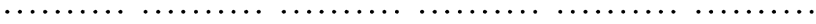

$190 \quad 200 \quad 210 \quad 220 \quad 230 \quad 240$

GATCGATGGC GCTCATTTCC TCGTTATTCT CAACAACGGT GTCCACTTTG GCGTCTACGC

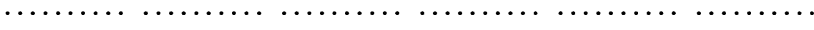



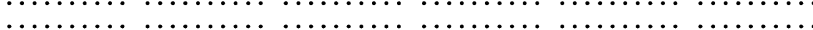

$\begin{array}{lllll}250 & 260 & 270 & 280 & 290\end{array}$

-TCACCTAGC TATCGCCCG ACCGTCGGTA GCGATGAAAg GTGGgGagAa AGTTCCTCTC

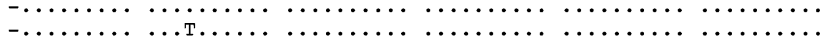

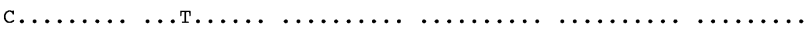

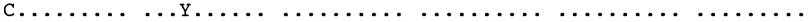

$\begin{array}{lllll}310 & 320 & 330 & 340 & 350\end{array}$

TATGAGTTGA GCAGACTTAA TGAGCCCTGC GTGAGGGCCG CCAAAACCCA AAACACAACC

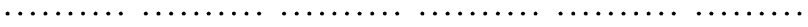

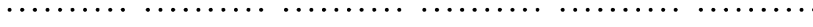

$\cdots \cdots \cdots \cdots \cdots \cdots \cdots \cdots \cdots \cdots$

$\begin{array}{cccccc}370 & 380 & 390 & 400 & 410 & 420\end{array}$

GTTTCTTTTC ATTTCCGAAG TTGACCGATG AGTCGAGGC TCCCGCTGT- CCATTCTTGG

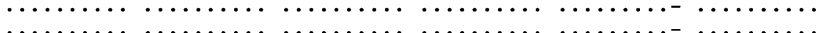

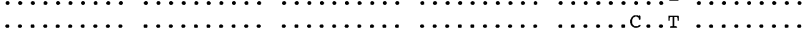

........

$\begin{array}{llllll}430 & 440 & 450 & 460 & 470 & 480\end{array}$

ATATGCGGGC GTGTTGATGA GTCGTTAACT AATATTCAAT ACTATCCGCA CAATGCTTCA

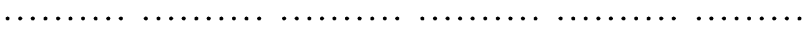

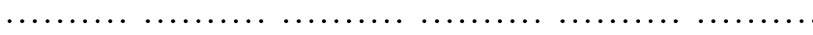

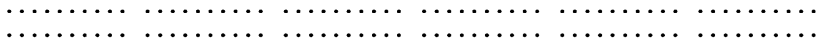

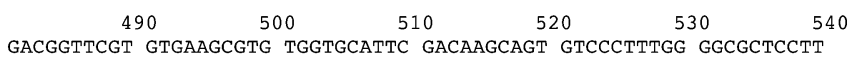

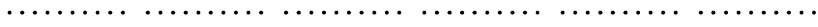

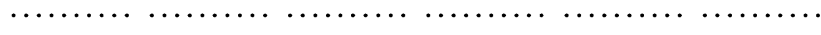

$\ldots \ldots \ldots+\ldots \ldots \ldots$

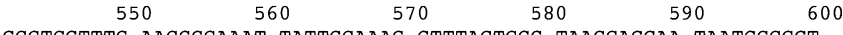

GCCTGGTTTG AACGGCAAAT TATTGCAAAG GTTTACTCGG TAAGCAGCAA TAATGGCCGT

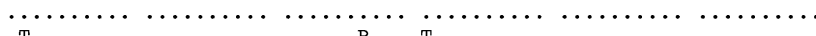

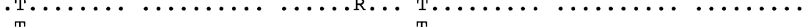

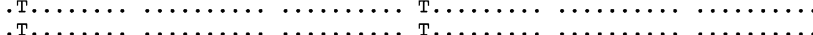

$\begin{array}{llllll}610 & 620 & 630 & 640 & 650 & 660\end{array}$

AAGTGTGAGA TTGATTGTGT ACGTCCCTCG ATGCGGCCCC CAGTATTTGT TGACTGCCTC

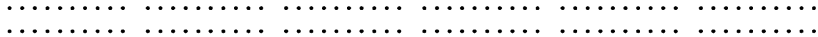

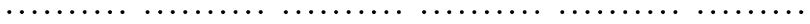

.......

$\begin{array}{lllll}670 & 680 & 690 & 700 & 710\end{array}$

TGGTGGTGAC TGGGGGTTAA GTATCGGATT ATCGAAAGA TGTGACATGT CTTATACGGT

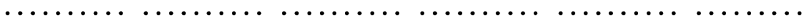

(2)

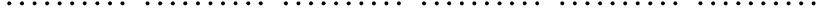

728

TATGTGCT

$\cdots \cdots \cdots$

$\ldots \ldots$

$\ldots \ldots$

FIGURE 3. Alignment of ITS-1 (positions 1-451) and ITS-2 (452-728) sequences representing C. ogmorhini s.1. taxa. Dots indicate identity with the first sequence and dashes are inferred insertion-deletion events; standard IUB ambiguity codes are used, i.e., $\mathrm{Y}=\mathrm{C} / \mathrm{T}, \mathrm{R}=\mathrm{A} / \mathrm{G}$. Contracaecum CSL 4966 and 4836 include the diversity of sequences found in 4 specimens from Zalophus californianus obtained from California waters. Sequences of Contracaecum ogmorhini s. str. from austral localities are represented by specimens from Arctocephalus pusillus pusillus (APP) and Arctocephalus pusillus doriferus (APD), whereas C. margolisi is from a Z. californianus from Pacific Canada. 
TABLE II. Pairwise nucleotide distances (absolute differences) for ITS-1, 5.8S, and ITS-2 sequences between Anisakis taxa.

\begin{tabular}{|c|c|c|c|c|c|c|c|c|c|c|c|c|c|}
\hline & 1 & 2 & 3 & 4 & 5 & 6 & 7 & 8 & 9 & 10 & 11 & 12 & 13 \\
\hline \multicolumn{14}{|l|}{ 1. A. typica } \\
\hline 2. A. sp. SSL 17 & 149 & & & & & & & & & & & & \\
\hline 4. A. sp. PRP C 140 & 149 & 0 & 2 & & & & & & & & & & \\
\hline 5. A. sp. PRP C140 & 149 & 0 & 2 & 0 & & & & & & & & & \\
\hline 6. A. sp. HP C141 & 149 & 3 & 5 & 3 & 3 & & & & & & & & \\
\hline 9. A. simplex $\mathrm{C}$. & 147 & 4 & 6 & 4 & 4 & 5 & 4 & 0 & & & & & \\
\hline 10. A. sp. NES 4 & 146 & 4 & 6 & 4 & 4 & 5 & 4 & 0 & 0 & & & & \\
\hline 11. A. sp. NES 2013 & 147 & 6 & 8 & 6 & 6 & 7 & 6 & 2 & 2 & 1 & & & \\
\hline 12. A. ziphidarum & 128 & 43 & 45 & 43 & 43 & 44 & 44 & 44 & 44 & 43 & 45 & & \\
\hline 13. A. physeteris & 153 & 129 & 131 & 129 & 129 & 129 & 130 & 132 & 132 & 131 & 132 & 128 & \\
\hline 14. A. brevispiculata & 144 & 126 & 128 & 126 & 126 & 124 & 125 & 124 & 124 & 123 & 124 & 123 & 37 \\
\hline
\end{tabular}

a large range of absolute distances (Table II), with many comparisons showing 2 or more differences. Comparisons involving Anisakis typica, Anisakis ziphidarum, Anisakis physeteris, or Anisakis brevispiculata yielded large pairwise distances. Two of 3 Anisakis specimens from $M$. angustirostris (NES) were identical with $A$. simplex $\mathrm{C}$, and these were the only matches between Anisakis reference ITS sequences and the 7 Anisakis from hosts inhabiting northern Pacific waters (Fig. 4). Identical sequences were found between 2 specimens from $L$. borealis (PRP) and 1 specimen from E. jubatus (SSL). This sample of 7 Anisakis individuals included 3 unique sequences from 5 individual nematodes (hosts SSL 17, PRP C140, HP C141, NES 2013) that did not match ITS sequences of A. brevispiculata, Anisakis simplex s. str., Anisakis simplex C., Anisakis pegreffii, A. physeteris, A. typica, and A. ziphidarum.

For the phylogenetic analysis of Anisakis taxa, using ProAlign to detect and remove unreliably aligned sites by their posterior probabilities excluded 198 of 922 ITS sites. This dataset of 724 characters included 96 phylogenetically informative characters. Maximum parsimony analysis of this ITS dataset yielded 3 most parsimonious trees of 240 steps (C.I. $=0.88$ ); ML analysis yielded 3 trees of equal likelihood. The strict consensus of the MP trees (Fig. 5) depicted A. physeteris plus A. brevispiculata as the sister group to the remaining Anisakis taxa. This clade was reliably supported in the MP bootstrap tree (92\%) but was not recovered in the ML bootstrap tree. The remaining 12 ingroup Anisakis were monophyletic in ML and MP consensus trees, with $100 \%$ bootstrap support. Anisakis taxa from hosts collected in northern Pacific waters were nested within the strongly supported clade that included $A$. pegreffii, A. simplex s. str., and A. simplex C. A clade including A. simplex s. str., A. pegreffii, and specimens from $P$. phocoena (HP), $L$. borealis (PRP), and E. jubatus (SSL) was recovered in the strict consensus of MP and ML trees and received moderate bootstrap support.

For the phylogenetic analysis of Pseudoterranova taxa, using ProAlign to detect and remove unreliably aligned sites excluded 83 of 681 ITS characters. This yielded a dataset of 598 characters that included 23 phylogenetically informative sites. Maximum parsimony analysis yielded 2 equally parsimonious trees of 114 steps $($ C.I. $=0.93)$; $\mathrm{ML}$ analysis recovered 2 trees of equal likelihood. A strict consensus of MP trees (Fig. 6) and 1 for ML trees depicted $P$. decipiens s.l. from Chaenocephalus aceratus (Blackfin icefish) as sister to the remaining taxa, which were supported as monophyletic with moderate support in MP and ML bootstrap analyses. Pseudoterranova specimens from hosts inhabiting northern Pacific waters were part of a clade in MP and ML consensus trees that included $P$. decipiens s. str. and $P$. azarasi.

\section{DISCUSSION}

Molecular approaches to delimiting and identifying anisakid nematodes have markedly influenced our understanding of their systematics and biodiversity (Paggi and Bullini, 1994; Bullini et al., 1997). For example, in a detailed morphologically based revision of Anisakis, Davey (1971) recognized 3 valid species (A. simplex, A. typica, and A. physeteris) and retained 4 others as species inquirendae (Anisakis dussumierii, Anisakis insignis, Anisakis schupakovi, and Anisakis alexandri). Multilocus allozyme methods, which have a long history of application to investigations of Anisakis diversity (Mattiucci et al., 1986; Nascetti et al., 1986; Orecchia et al., 1986; Paggi and Bullini, 1994; Bullini et al., 1997), have independently supported the validity of A. simplex s. str., A. typica, A. physeteris, and A. schupakovi, plus other species not recognized as valid by Davey (1971), such as A. brevispiculata (Mattiucci et al., 2001). These methods have also proved to be powerful tools for revealing cryptic Anisakis species, such as members of the A. simplex complex, including $A$. simplex $\mathrm{C}$ and $A$. pegreffii.

Multilocus protein electrophoresis with population-level sampling of Anisakis, Contracaecum, and Pseudoterranova has been used to detect evidence of distinct biological species in natural populations and develop allozyme keys for their identification (Mattiucci et al., 1997, 1998; Paggi et al., 2000). Reference individuals initially characterized by allozymes have also been used to develop DNA-based approaches for species identification such as PCR-RFLP and direct sequencing of ITS rDNA or mitochondrial DNA. For molecular systematics, multilocus approaches offer significant theoretical advantages for 
A. simplex s. str.

A. simplex $\mathrm{C}$

A. pegreffii

A. ziphidarum

A. physeteris

A. brevispiculata

A. typica

Anisakis sp. PRP C 140

Anisakis sp. HP C 141

Anisakis sp. NES 2013

A. simplex s. str.

A. simplex $\mathrm{C}$

A. pegreffii

A. ziphidarum

A. physeteris

A. brevispiculata

A. typica

Anisakis sp. PRP C 140

Anisakis sp. HP C 141

Anisakis sp. NES 2013
A. simplex s. str.
A. simplex $\mathrm{C}$
A. pegreffii
A. ziphidarum
A. physeteris
A. brevispiculata
A. typica
Anisakis sp. PRP C140
Anisakis sp. HP C141
Anisakis sp. NES 2013
A. simplex s. str.
A. simplex $\mathrm{C}$
A. pegreffii
A. ziphidarum
A. physeteris
A. brevispiculata
A. typica
Anisakis sp. PRP C140
Anisakis HP C141
Anisakis sp. NES 2013
A. simplex s. str.
A. simplex $\mathrm{C}$
A. pegreffii
A. ziphidarum
A. physeteris
A. brevispiculata
A. typica
Anisakis sp. PRP C140
Anisakis sp. HP C141
Anisakis sp. NES 2013

$\begin{array}{llllll}310 & 320 & 330 & 340 & 350 & 360\end{array}$

GACTTAATGA GCCACG--CT AGGTGGCCGC CAAAACCCAA AACACAACCG GTCTATTTGA

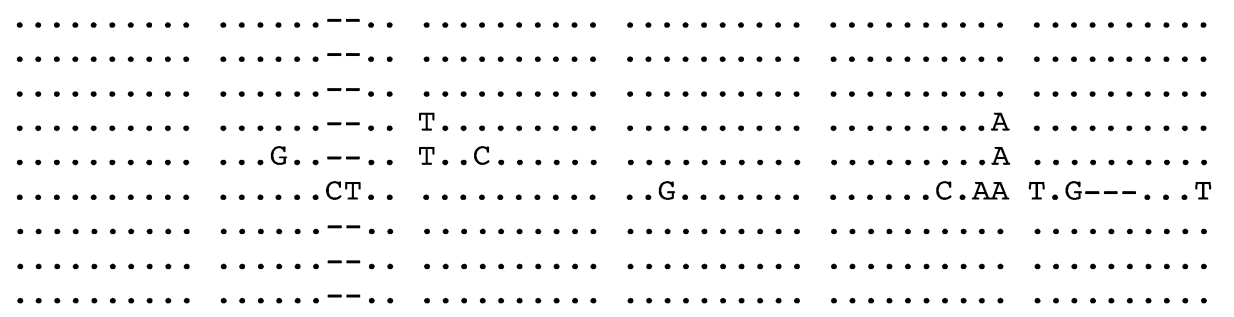

$\begin{array}{llllll}370 & 380 & 390 & 400 & 410 & 420\end{array}$

CATTGTTA-- TTTCATTGTA TGTGTTGAAA ATGTATTACG GTGAACTGTC TTCACG-GTT

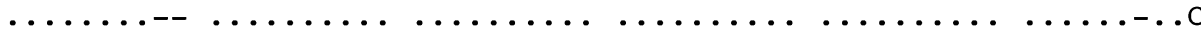

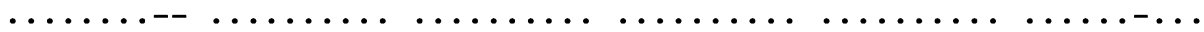

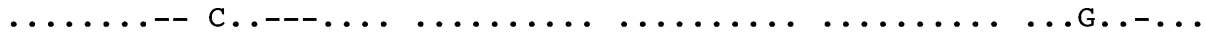

$\ldots \ldots$. . . A.GCG.TG. CA.TAC.TT. ...... . . ........ . . .--

$\ldots \ldots$... . A.GCG.TG. CA.TA..TT. ..................---

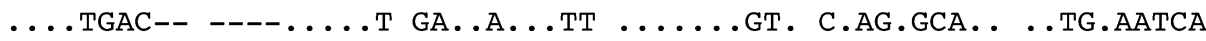

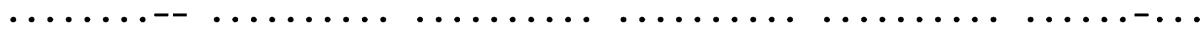

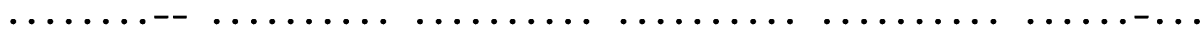

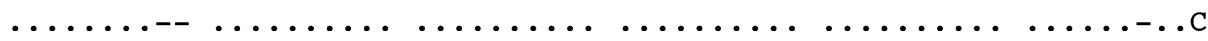

$430 \quad 440 \quad 450 \quad 460 \quad 470 \quad 480$

TTTCT----- ----GGACTG TGAAGCATTC GGCAAGCAAT TGCTGTTGTG TTGTTGGTGA

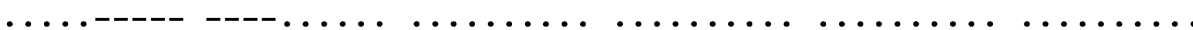

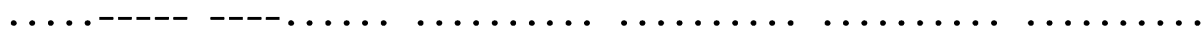

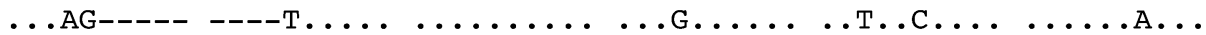

-GCTC----- ----C.G.C. ...........................-.T

-G.T.---- ---C.G..........................-.T

С....тСАG АТTGT..............................

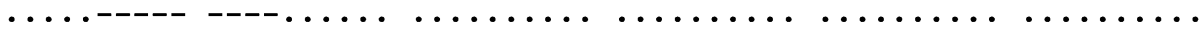

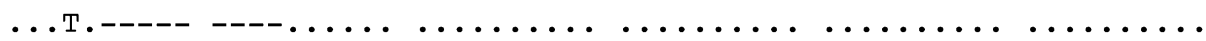

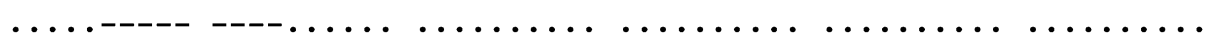

$490 \quad 500 \quad 510 \quad 520 \quad 530 \quad 540$

TTCTATCATG G-------- --ACAATATG ACGAGCGGTT CCTTGCTTAG TG--ATGAC-

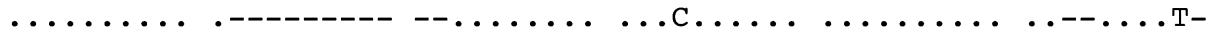

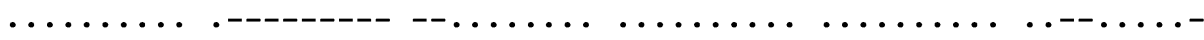

. GAG..-- .--

.GG.---- --

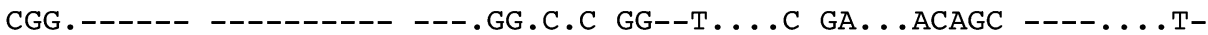

AGG.GA.GAT TGAATCGGCA CCG.GCG.CA CGACA............ TTG.... AC

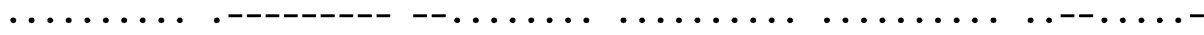

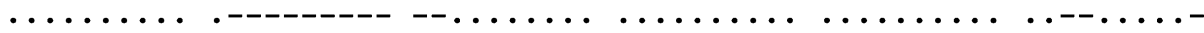

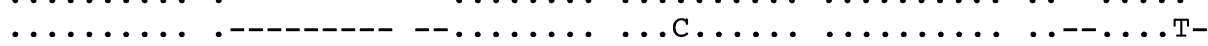

\begin{tabular}{|c|c|c|c|c|c|}
\hline 5 & 56 & 57 & 58 & 30 & 90 \\
\hline AGAAGA & CGTCAACACC & GАATCTACTA & $\mathrm{TA}------\mathrm{CT}$ & АСТААТАСТА & GTATATAGGT \\
\hline & & . & & $\cdots \cdots$ & $\cdots \ldots \ldots$ \\
\hline & & - & & - & - \\
\hline G...... & & $\ldots c$ & ..---ー-ー. & $\cdots$ & .... \\
\hline.$----- \mathrm{GCTC}$ & .T.G & TGT & GG------AG & $\ldots A C$ &.$-- A$ \\
\hline -----.GCTC & .T.GCTT.GT & TGT.G.GTG. & AG------AG & . GTTA..AC & $\mathrm{C}-\mathrm{GA} \cdot \mathrm{C}--\cdot \mathrm{G}$ \\
\hline A...... &. CCGC ..... & C..CG.CTGC & . AACACTAG & ....GAG..G & $\ldots$ G.C...AG \\
\hline$\cdots \cdots \cdots$ & $\ldots \ldots \ldots$ & $\cdots \cdots \cdots$ & ••---ー-ー & $\cdots \cdots \cdots$ & $\cdots \cdots$ \\
\hline$\cdots \cdots \cdots$ & $\cdots \cdots \cdots$ & $\cdots \cdots$ & 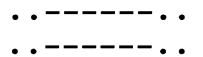 & $\cdots \cdots \cdots$ & $\ldots \ldots$ \\
\hline
\end{tabular}

FIGURE 4. Alignment of ITS-1 (positions 1-395) and ITS-2 (396-765) sequences of Anisakis taxa. One representative of each unique sequence was included for comparison. Dots indicate identity with the first sequence and dashes are inferred insertion-deletion events. 
A. simplex s. str.

A. simplex $\mathrm{C}$

A. pegreffii

A. ziphidarum

A. physeteris

A. brevispiculata

A. typica

Anisakis sp. PRP C140

Anisakis sp. HP C141

Anisakis sp. NES 2013

A. simplex s. str.

A. simplex $\mathrm{C}$

A. pegreffii

A. ziphidarum

A. physeteris

A. brevispiculata

A. typica

Anisakis sp. PRP C140

Anisakis sp. HP C141

Anisakis sp. NES 2013

A. simplex s. str.

A. simplex $\mathrm{C}$

A. pegreffii

A. ziphidarum

A. physeteris

A. brevispiculata

A. typica

Anisakis sp. PRP C140

Anisakis sp. HP C141

Anisakis sp. NES 2013

A. simplex s. str.

A. simplex $\mathrm{C}$

A. pegreffii

A. ziphidarum

A. physeteris

A. brevispiculata

A. typica

Anisakis sp. PRP C 140

Anisakis HP C141

Anisakis sp. NES 2013

A. simplex s. str.

A. simplex C

A. pegreffii

A. ziphidarum

A. physeteris

A. brevispiculata

A. typica

Anisakis sp. PRP C140

Anisakis sp. HP C141

Anisakis sp. NES 2013 $\begin{array}{llllll}310 & 320 & 330 & 340 & 350 & 360\end{array}$

GACTTAATGA GCCACG--CT AGGTGGCCGC CAAAACCCAA AACACAACCG GTCTATTTGA

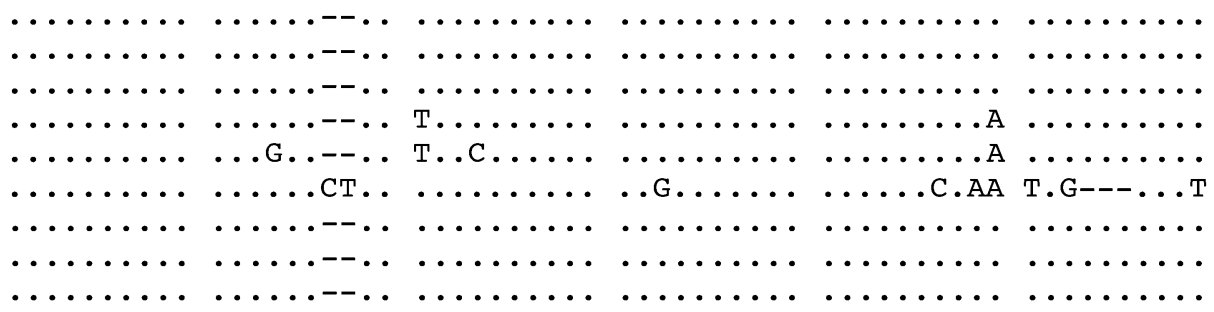

$\begin{array}{llllll}370 & 380 & 390 & 400 & 410 & 420\end{array}$

CATTGTTA-- TTTCATTGTA TGTGTTGAAA ATGTATTACG GTGAACTGTC TTCACG-GTT

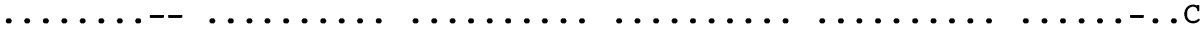

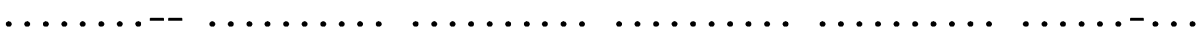

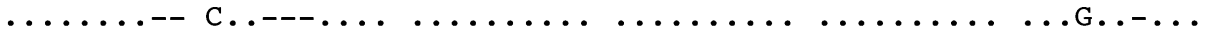

$\ldots \ldots$. . . A .GCG.TG. CA.TAC.TT. ...... .CA........GT.---

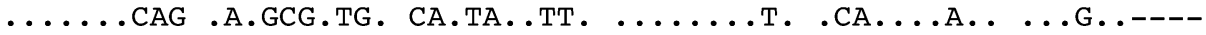

$\ldots$. .TGAC-- --....T GA..A...TT ......GT. C.AG.GCA.. . TG.AATCA

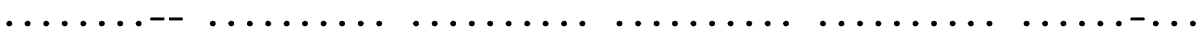

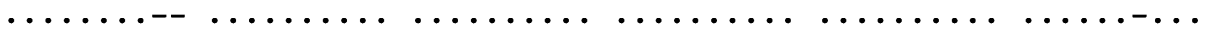

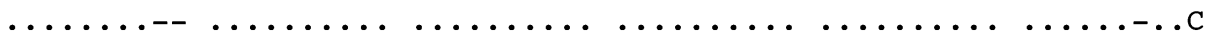

$430 \quad 440 \quad 450 \quad 460 \quad 470 \quad 480$

TTTCT---- ----GGACTG TGAAGCATTC GGCAAGCAAT TGCTGTTGTG TTGTTGGTGA

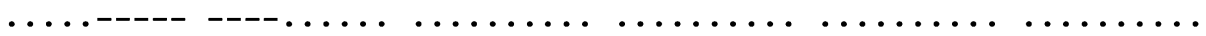

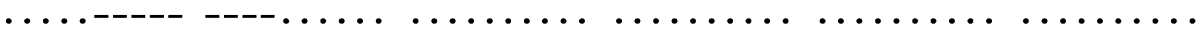

$\ldots$ AG--- - - $\ldots$. ............................

-GCTC---- ----C.G.C. ...........................-.T

-G.T.---- ---C.G............................ . . .

С...СTСAG АТTGT... ..........................

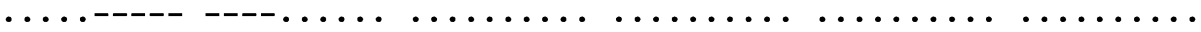

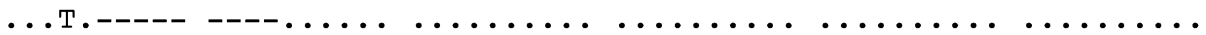

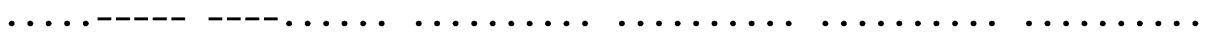

$490 \quad 500 \quad 510 \quad 520 \quad 530 \quad 540$

TTCTATCATG G------- --ACAATATG ACGAGCGGTT CCTTGCTTAG TG--ATGAC-

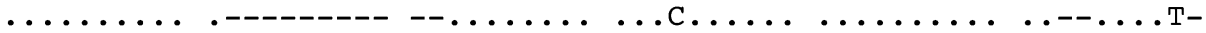

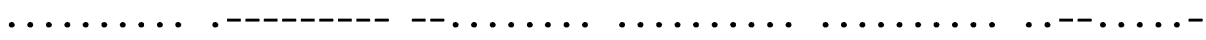

. GAG..-- .--

.GG.---- CGG.--n- - -

AGG.GA.GAT TGAATCGGCA CCG.GCG.CA CGACA........... .TTG.... AC

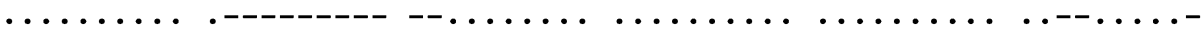

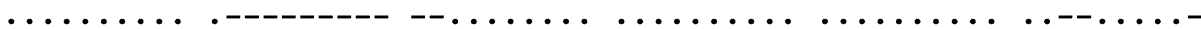

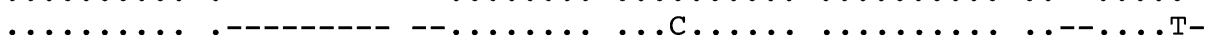
$\begin{array}{llrrr}550 & 560 & 570 & 580 & 590\end{array}$ -AAAAGAAGA CGTCAACACC GAATCTACTA TA------CT ACTAATACTA GTATATAGGT

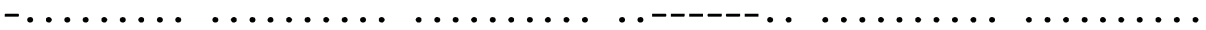
$-\ldots \ldots \ldots \ldots \ldots \ldots \ldots \ldots \ldots \ldots \ldots \ldots \ldots \ldots \ldots$

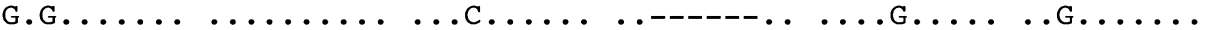
. . .GCTT.GT TGT.G.GTG. GG----AG ..GTCA..AC C-GA.C--.A ----.GCTC .T.GCTT.GT TGT.G.GTG. AG-----AG ..GTTA..AC C-GA.C--.G А.....С.T .CCGC.... С..CG.CTGC ..AACACTAG ...GAG..G ..G.C...AG

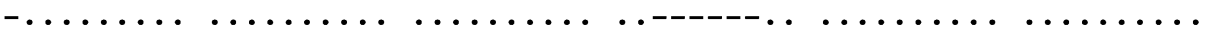

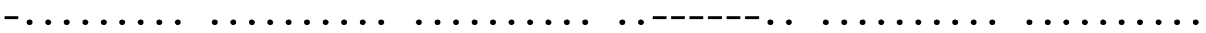
А................ . .....---..............

Figure 4. Continued. 


A. simplex s. str.
A. simplex C
A. pegreffii
A. ziphidarum
A. physeteris
A. brevispiculata
A. typica
Anisakis sp. PRP C140
Anisakis sp. HP C141
Anisakis sp. NES 2013

A. simplex s. str.

A. simplex $\mathrm{C}$

A. pegreffii

A. ziphidarum

A. physeteris

A. brevispiculata

A. typica

Anisakis sp. PRP C140

Anisakis sp. HP C 141

Anisakis sp. NES 2013
A. simplex s. str.
A. simplex $\mathrm{C}$
A. pegreffii
A. ziphidarum
A. physeteris
A. brevispiculata
A. typica
Anisakis sp. PRP C140
Anisakis sp. HP C141
Anisakis sp. NES 2013

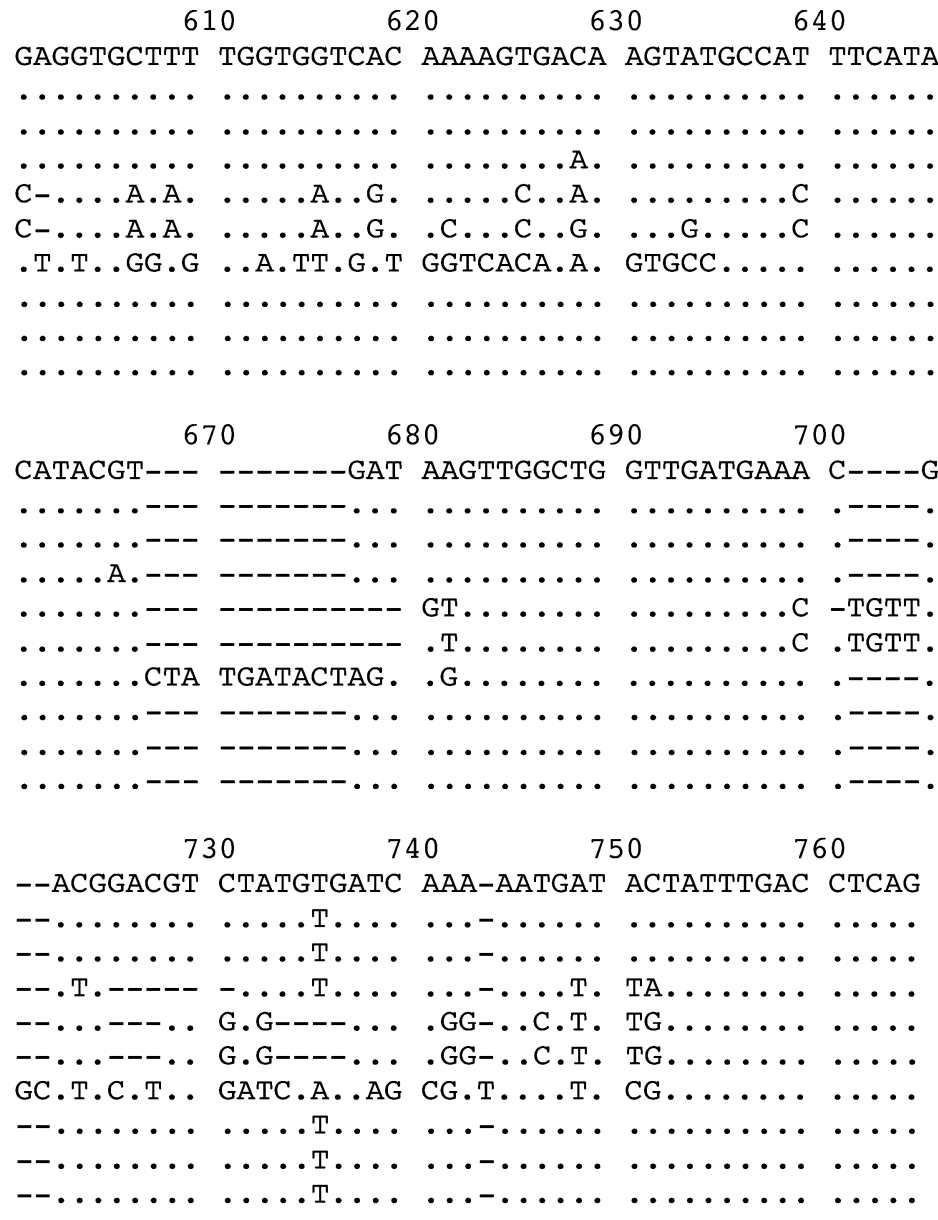

Figure 4. Continued. detecting and delimiting species when investigating natural populations (Nadler, 2002, 2005), whereas DNA diagnostic markers based on a single locus are most useful as practical tools for identification of known species from either larvae or adults. Single-locus studies based on sequencing or SSCP methods have the potential to reveal previously uncharacterized genetic variation, as in this study. However, interpreting this variation is often difficult, in particular, when relatively few individuals have been studied. Although such unique genetic variants may represent the derived states characteristic of distinct evolutionary species (and the markers of noninterbreeding populations as inferred for biological species), an alternative interpretation is that they represent intraspecific polymorphisms. When the genetic differentiation between known species and newly discovered genetic variants is large, it is tempting to hypothesize that the new variant represents an uncharacterized species, even when these data come from 1 locus. More typically, there are few differences between new variants and known species, as in this study, and multilocus studies of population samples are required to assess whether the genetic differences are fixed and the pattern consistent with separate species. Nevertheless, discovering novel sequences, as reported here for specimens of Anisakis and Contracaecum, is valuable because it reveals that previously unrecognized species may exist. Genetic data for fully testing hypotheses of new species (species delimitation) must come from additional research, such as comparisons of nucleotide sequences from multiple loci (and interpretation of multiple gene trees) or from multilocus protein electrophoresis (and population genetic analysis).

Pseudoterranova adults collected from hosts inhabiting northern Pacific waters, including $Z$. californianus (CSL), $M$. angustirostris (NES), P. vitulina (HS), E. lutris (SO), and E. jubatus (SSL), had LSU and ITS sequences that were identical with $P$. decipiens s. str. (formerly called $P$. decipiens $\mathrm{B}$ ). These results represent new host records for $P$. decipiens s. str. in $M$. angustirostris, E. lutris, and E. jubatus, extending the confirmed host and geographic range of this anisakid, which is geographically widespread in pinniped hosts of the Northern Hemisphere. Surveys of marine mammals from Pacific waters using morphological approaches have reported $P$. decipiens s.l. or Pseudoterranova sp. from these same hosts plus C. ursinus (NFS), in which it has a high prevalence (Spraker et al., 2003). Pseudoterranova decipiens s. str. is 1 of 4 species from the $P$. decipiens complex, which also includes Pseudoterranova bulbosa, Pseudoterranova krabbei, and P. azarasi (Mattiucci et al., 1998; Paggi et al., 2000). The latter was redescribed based on specimens from E. barbatus (BS) and E. jubatus (SSL) collected in Japanese waters of the northern Pacific Ocean. These investigators tested 237 individual adult $P$. decipiens s.l. from these 2 host species using allozyme electrophoresis and only 


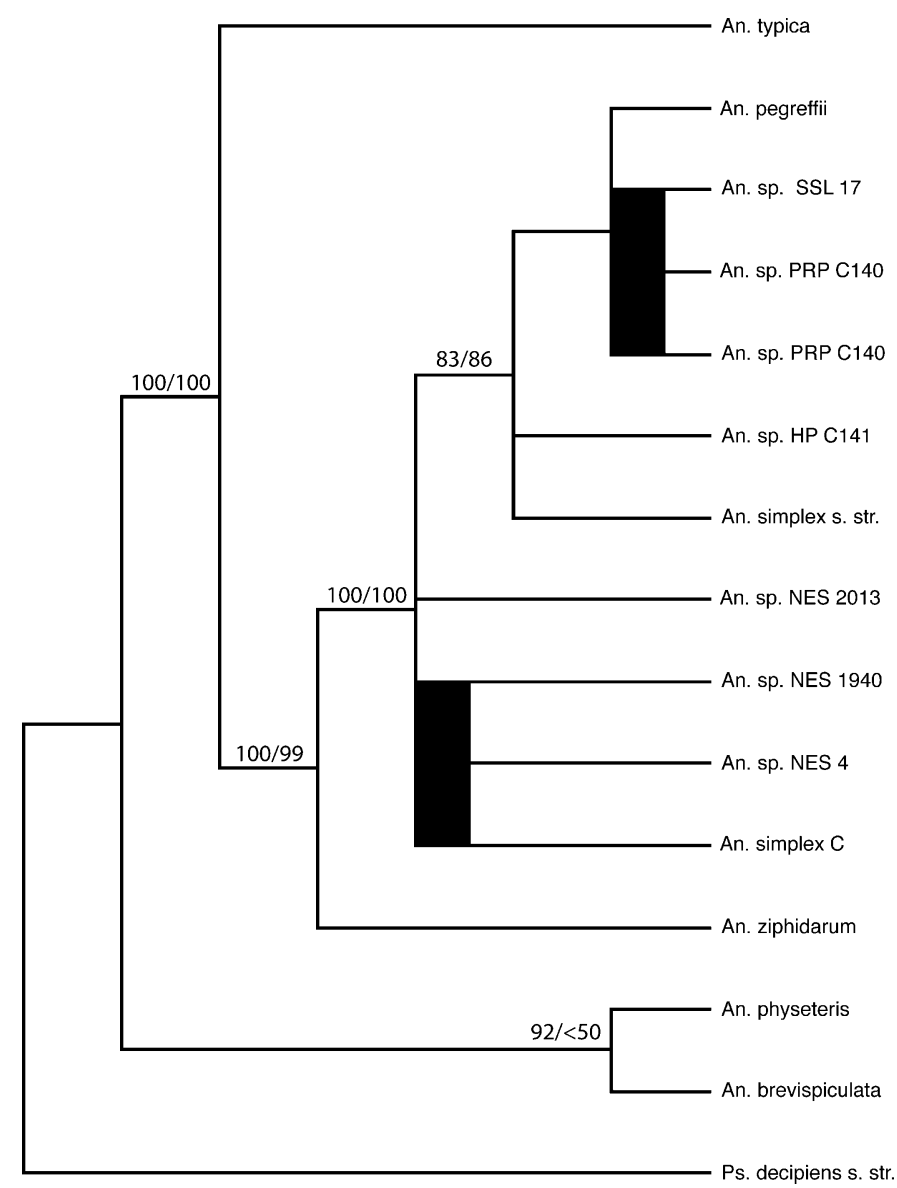

FIGURE 5. Strict consensus of 3 equally parsimonious trees inferred from Anisakis ITS rDNA sequences. Trees inferred using unweighted MP from a ProAlign alignment after excluding sites with minimum posterior probabilities of $60 \%$ or less (198 of 922 sites). These 3 MP trees required 240 steps and had a C.I. of 0.88 . Bootstrap percentages of clades $(\geq 70 \%)$ are shown above internal nodes, with MP values listed first, followed by ML values. Vertical black bars mark Anisakis taxa with identical ITS sequences as inferred from pairwise comparison of the alignment without exclusion of sites. Tree rooted by Pseudoterranova decipiens s. str. sequence. Abbreviations for host species and individual host identifier follow selected parasite species: HP (harbor porpoise), NES (northern elephant seal), PdCa (blackfin icefish), PdOe (european smelt), PRP (Pacific rightwhale porpoise), SSL (Steller's sea lion).

found individuals of $P$. bulbosa and $P$. azarasi. Although $P$. azarasi was not found in the small sample of nematodes examined in these North American hosts, 1 individual was polymorphic for the only ITS site that distinguishes $P$. azarasi from $P$. decipiens s. str. Additional research is needed to determine if this site is polymorphic within $P$. decipiens s. str. or $P$. azarasi (compromising the diagnostic utility of this ITS site in this case), or alternatively if this individual represents an F1 hybrid. Genetic evidence has revealed 1 instance of hybridization between P. decipiens s. str. and P. krabbei (Paggi et al., 1991), and hybridization of other anisakids has been suggested based on ITS sequences (Abollo et al., 2003).

Previous systematic analyses of Pseudoterranova species have included comparisons based on allozyme genetic distances (Paggi et al., 1991; Bullini et al., 1997; Paggi et al., 2000) and a phenogram of uncorrected ITS rDNA distances (Zhu et al., 2002). The allozyme studies indicated a close genetic relationship between $P$. decipiens s. str. and $P$. azarasi (Bullini et al., 1997; Paggi et al., 2000), with the topology: ((( $P$. decipiens s. str., P. azarasi), P. krabbei), P. bulbosa), P. decipiens E) (Bullini et al., 1997). Considering only taxa that were identified to species, the ITS phenogram (Zhu et al., 2002) also depicted greatest similarity between $P$. decipiens s. str. and $P$. azarasi; however, their ITS phenogram was different from the allozyme tree: $(((((P$. decipiens s. str., $P$. azarasi $), P$. bulbosa $), P$. cattani), P. krabbei), P. decipiens Ca1). Zhu et al. (2002) have hypothesized that $P$. decipiens $\mathrm{Ca} 1$ is most likely equivalent to $P$. decipiens E. Maximum parsimony and ML analyses of ITS sequences (Fig. 6) also depicted a clade including $P$. azarasi and $P$. decipiens s. str.; however, the remaining topology was different from the previously published ITS analysis but was the same as the allozyme phenogram (excepting the absence of $P$. cattani from the allozyme study). Differences between these 2 analyses of ITS sequences are not unexpected, given that methods of inferring phenograms and phylogenetic trees involve very different assumptions. One potentially interesting phylogenetic result is that the Southern Hemisphere Pseudoterranova $\mathrm{Ca} 1$ and $P$. cattani are not sister taxa, suggesting a more complex evolutionary history than might be explained by a simple biogeographic scenario.

Contracaecum adults collected from Z. californianus (CSL) hosts inhabiting northern Pacific waters were identical in LSU 


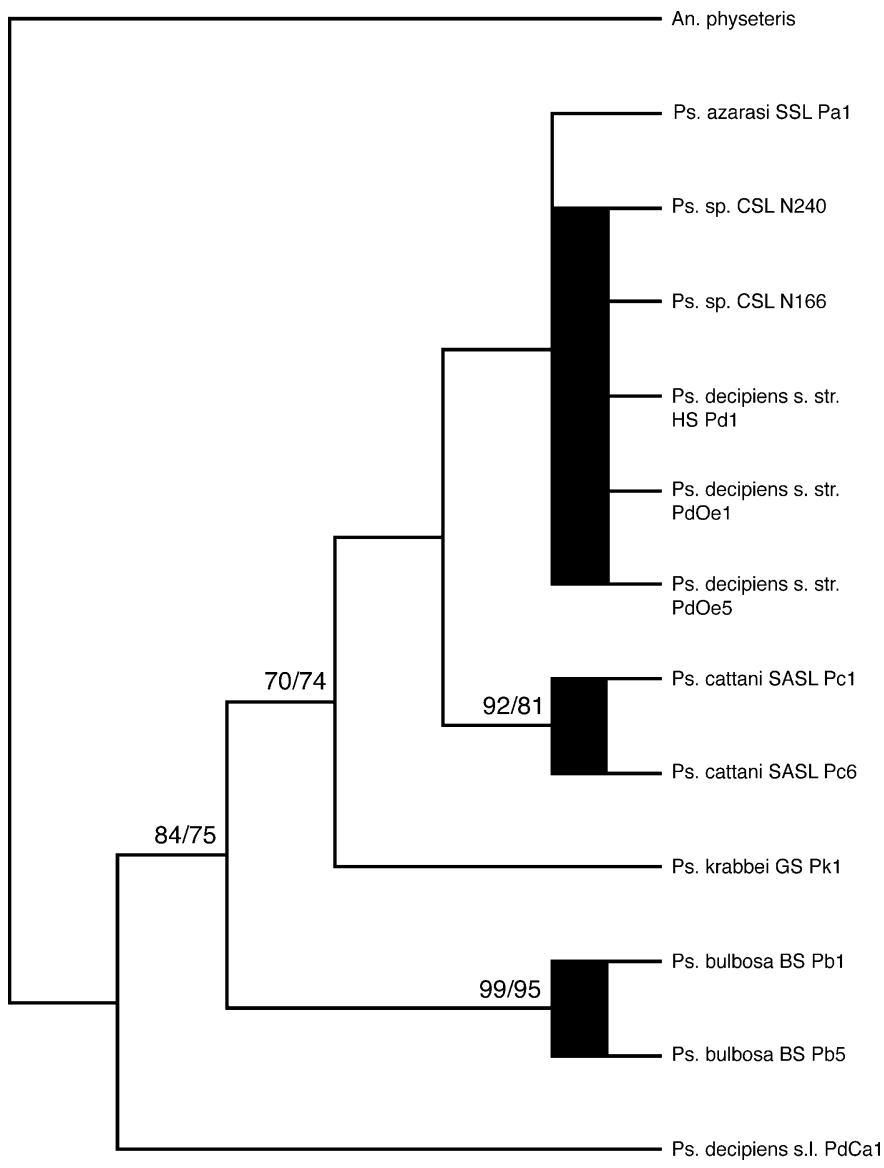

FIGURE 6. Strict consensus of 2 equally parsimonious trees inferred from Pseudoterranova ITS rDNA sequences. Only 2 of 8 new Pseudoterranova sequences representing hosts from northern Pacific waters were included; these sequences represented all the variation among these 8 sequences. Vertical black bars mark taxa with identical ITS sequences as inferred from pairwise comparison of the alignment without exclusion of sites. Trees inferred using unweighted MP from a ProAlign alignment after excluding sites with minimum posterior probabilities of $60 \%$ or less (83 of 681 sites). These MP trees required 114 steps and had a C.I. of 0.93 . Bootstrap percentages of clades ( $\geq 70 \%)$ are shown above internal nodes, with MP values listed first, followed by ML values. Abbreviations for host species and individual host identifier follow selected parasite species: BS (bearded seal), CSL (California sea lion), GS (grey seal), HS (harbor seal), NES (northern elephant seal), PdCa (blackfin icefish), PdOe (european smelt), PRP (Pacific rightwhale porpoise), SASL (South American sea lion), SSL (Steller's sea lion).

sequence with $C$. ogmorhini s. str., but their ITS sequences matched neither $C$. ogmorhini s. str. nor $C$. margolisi. This apparent conflict between LSU and ITS rDNA can be explained by the more conservative substitution rate of this LSU region. All 4 Contracaecum individuals from Z. californianus differed from $C$. margolisi and $C$. ogmorhini s. str. at 1 site; 4 other ITS-1 site differences were noted, but the nature of these differences suggest they may represent errors in the previously published sequences. One individual specimen was polymorphic at the only ITS-1 site that is different between C. ogmorhini s. str. and $C$. margolisi. Although this individual nematode would not be confused with $C$. ogmorhini s. str. or C. margolisi due to the difference in ITS sequence at position 407 (Fig. 3), the presence of such site polymorphisms in the few individuals of $C$. ogmorhini s.l. examined indicates that more individuals should be sequenced to confirm that sites with differences are fixed within species. From a phylogenetic perspective, the LSU analysis establishes that the Contracaecum from these $Z$. californianus is most closely related to $C$. ogmorhini s.l. and $C$. rudolphii. Phylogenetic analysis of ITS sequences was not un- dertaken for Contracaecum because of the potential sequence errors previously noted and the lack of ITS variation (Fig. 3). Additional genetic studies are required to determine whether these novel sequences from California sea lion hosts represent a previously unrecognized species.

Anisakis adults collected from northern Pacific marine mammals included individuals of $A$. simplex $\mathrm{C}$ from $2 \mathrm{M}$. angustirostris (NES) hosts; this is a new host record for this species. None of the other 5 individuals had ITS sequences that matched known species. Specimens from L. borealis (PRP) and E. jubatus (SSL) were most closely related to A. pegreffii, as inferred from phylogenetic analysis of ITS rDNA. The unique sequence from $P$. phocoena (HP) was part of the clade that included $A$. pegreffii and $A$. simplex s. str. All the specimens from northern Pacific marine mammals were nested within the clade that included ((A. pegreffii, A. simplex s. str.) A. simplex $\mathrm{C})$; these represent the 3 known species within the $A$. simplex species complex and are characterized (along with A. typica and $A$. ziphidarum) by having type I larvae sensu Berland (1961), which may represent the apomorphic (derived) state within An- 
isakis. Thus, these 3 unique ITS sequences may represent previously unidentified species of the A. simplex complex, but testing this hypothesis will require additional data. Previously published assessments of Anisakis relationships have been based on analysis of allozyme data (Bullini et al., 1997; Mattiucci et al., 1997; Paggi, Mattiucci et al., 1998; Mattiucci et al., 2002). Allozyme studies that have included explicit trees have indicated that a close genetic relationship exists among species of the A. simplex complex, with phenograms depicting the topology: ((((A. simplex s. str., A. simplex $\mathrm{C})$, A. pegreffii $),$ A. ziphidarum), A. physeteris) (Mattiucci et al., 1997; Paggi, Nascetti et al., 1998). In contrast to these multilocus phenograms, the MP and ML analyses of ITS sequences supported a sister-group relationship for $A$. pegreffi $i$ and $A$. simplex s. str., with $A$. simplex $\mathrm{C}$ as sister to this clade (Fig. 5). Although the ITS phylogeny contains more species than in the published allozyme phenograms, there is good agreement between phenetic clustering of allozyme data and phylogenetic analysis of ITS sequences.

Molecular phylogenetic studies of anisakids and other "aquatic" ascaridoids have been relatively limited with respect to species representation (Nadler and Hudspeth, 1998; Nadler et al., 2000; Nadler and Hudspeth, 2000). Phylogenetic support for Anisakidae and Raphidascarididae has varied according to both the genes analyzed and the types of analytical methods used (Nadler and Hudspeth, 1998; Zhu, Gasser, and Chilton, 1998; Nadler and Hudspeth, 2000; Shih, 2004). For example, phylogenetic analyses of SSU or LSU sequences recovered a raphidascarid clade, but did not find evidence of a monophyletic Anisakidae, whereas combined analysis of SSU and LSU sequences yielded a monophyletic Anisakidae using ML inference but not by MP (Nadler and Hudspeth, 1998). Such problems may be addressed by adding taxa, or characters, or both (Graybeal, 1998; Mitchell et al., 2000); however, in the most comprehensive phylogenetic analysis of Ascaridoidea, which included data from 3 genes plus morphological characters, support for the anisakid clade remained weak (Nadler and Hudspeth, 2000). To provide increased taxon representation, published and new $28 \mathrm{~S}$ sequences were combined in an analysis that used a probabilistic approach to determine which sites were ambiguous with respect to multiple alignment and warranted exclusion from the phylogenetic analyses. In these analyses, Contracaecum diversity was well represented, and raphidascarids included 4 of 9 genera. Anisakinae was less well represented, with only members of the A. simplex complex, Terranova, and 1 species of Pseudoterranova. The latter genus shows relatively little ITS diversity among known species (Zhu et al., 2002), and, therefore, additional Pseudoterranova 28 S sequences are unlikely to substantially alter the LSU tree. In contrast, Anisakis taxa show substantial ITS sequence diversity (Fig. 4), and because species with the most divergent ITS sequences $(A$. typica, A. physeteris, A. brevispiculata) are absent from the LSU trees, these trees cannot be considered definitive statements about Anisakis monophyly. Parsimony and ML analyses indicated that the Raphidascarididae, Contracaecum plus Phocascaris, and Anisakinae (Pseudoterranova, Anisakis, Terranova) are each monophyletic, the latter 2 groups with consistently strong (MP and ML) bootstrap support. Anisakidae was recovered in the ML analysis, but without reliable bootstrap support; this clade was absent from the MP tree. In general, clade support was weak at deeper nodes in the LSU gene tree as evidenced by low bootstrap values for both MP and ML. In this case, adding taxa did not appear to increase the resolution of rDNA trees when testing the monophyly of the Anisakidae or Ascarididae. Improving phylogenetic resolution for deeper nodes in the evolutionary history of Ascaridoidea will apparently require additional gene sequences, perhaps those with relatively conservative rates of evolutionary change (Nadler, 1995).

\section{ACKNOWLEDGMENTS}

We thank Derek Hyman and Eugene Bolotin for assistance with contig assembly and database management. This study was supported in part by NSF Tree of Life grant DEB-0228692.

\section{LITERATURE CITED}

Abollo, E., L. Paggi, S. Pascual, and S. D’ Amelio. 2003. Occurrence of recombinant genotypes of Anisakis simplex s.s. and Anisakis pegreffii (Nematoda: Anisakidae) in an area of sympatry. Infection, Genetics and Evolution 3: 175-181.

ADAMS, B. J. 1998. Species concepts and the evolutionary paradigm in modern nematology. Journal of Nematology 30: 1-21.

Baeza, M. L., V. Matheu, A. Rodriguez, M. De Barrio, P. Tornero, M. Rubio, AND J. M. ZubeldiA. 2001. Excretory-secretory Anisakis simplex allergens: In vivo and in vitro studies. Journal of Allergy and Clinical Immunology 107: S184.

Berland, B. 1961. Nematodes from some Norwegian marine fishes. Sarsia 2: 1-50.

Brattey, J., AND W. S. DAvidson. 1996. Genetic variation within Pseudoterranova decipiens (Nematoda: Ascaridoidea) from Canadian Atlantic marine fishes and seals: Characterization by RFLP analysis of genomic DNA. Canadian Journal of Fisheries and Aquatic Sciences 53: 333-341.

, AND I.-H. Ni. 1992. Ascaridoid nematodes from the stomach of harp seals, Phoca groenlandica, from Newfoundland and Labrador. Canadian Journal of Fisheries and Aquatic Sciences 49: 956966.

, AND G. B. Stenson. 1993. Host-specificity and abundance of parasitic nematodes (Ascaridoidea) from the stomachs of 5 phocid species from Newfoundland and Labrador. Canadian Journal of Zoology 71: 2156-2166.

Bullini, L., P. Arduino, R. Cianchi, G. Nascetti, S. D’Amelio, S. Mattiucci, L. Paggi, P. Orecchia, J. Plotz, B. Berland, J. W. SMITH, AND J. BRATTEY. 1997. Genetic and ecological research on Anisakid endoparasites of fish and marine mammals in the Antarctic and Arctic-boreal regions. In Antarctic communities: Species, structure, and survival, B. Battaglia, J. Valencia, and D. W. H. Walton (eds.). Cambridge University Press, Cambridge, U.K., p. $39-44$.

D’Amelio, S., K. D. Mathiopoulos, C. P. Santos, O. N. Pugachev, S. C. Webb, M. PicAnço, And L. Paggi. 2000. Genetic markers in ribosomal DNA for the identification of members of the genus $A n-$ isakis (Nematoda: Ascaridoidea) defined by polymerase chain reaction-based restriction fragment length polymorphism. International Journal for Parasitology 30: 223-226.

DAVEy, J. T. 1971. A revision of the genus Anisakis Dujardin, 1845 (Nematoda: Ascaridata). Journal of Helminthology 45: 51-72.

Di Deco, M. A., P. Orecchia, L. Paggi, and V. Petrarca. 1994. Morphometric stepwise discriminant analysis of three genetically identified species within Pseudoterranova decipiens (Krabbe, 1878) (Nematoda: Ascaridida). Systematic Parasitology 29: 81-88.

FAGERHOLM, H. P., AND D. I. GiBSON. 1987. A redescription of the pinniped parasite Contracaecum ogmorhini (Nematoda, Ascaridoidea), with an assessment of its antiboreal circumpolar distribution. Zoologica Scripta 16: 19-24.

Gasser, R. B., L. E. Stewart, and R. Speare. 1996. Genetic markers in ribosomal DNA for hookworm identification. Acta Tropica 62: $15-21$.

George-Nascimento, M., AND X. Urrutia. 2000. Pseudoterranova cat- 
tani sp nov (Ascaridoidea: Anisakidae), a parasite of the South American sea lion Otaria byronia De Blainville from Chile. Revista Chilena De Historia Natural 73: 93-98.

GRAYBEAL, A. 1998. Is it better to add taxa or characters to a difficult phylogenetic problem? Systematic Biology 47: 9-17.

Hu, M., S. D’Amelio, X. Q. Zhu, L. Paggi, and R. Gasser. 2001. Mutation scanning for sequence variation in three mitochondrial DNA regions for members of the Contracaecum osculatum (Nematoda: Ascaridoidea) complex. Electrophoresis 22: 1069-1075.

KiJewska, A., J. Rokicki, J. SitKo, AND G. Wegrzyn. 2002. Ascaridoidea: A simple DNA assay for identification of 11 species infecting marine and freshwater fish, mammals, and fish-eating birds. Experimental Parasitology 101: 35-39.

Löytynoja, A., And M. C. Milinkovitch. 2003. A hidden Markov model for progressive multiple alignment. Bioinformatics 19: 15051513.

Mattiucci, S., R. Cianchi, G. Nascetti, L. Paggi, N. Sardella, J. Timi, S. C. Webb, R. Bastida, D. Rodriguez, And L. Bullini. 2003. Genetic evidence for two sibling species within Contracaecum ogmorhini Johnston \& Mawson, 1941 (Nematoda : Anisakidae) from otariid seals of boreal and austral regions. Systematic Parasitology 54: 13-23.

- G. Nascetti, L. Bullini, P. Orecchia, And L. Paggi. 1986. Genetic structure of Anisakis physeteris, and its differentiation from the Anisakis simplex complex (Ascaridida, Anisakidae). Parasitology 93: 383-387.

- R. Cianchi, L. Paggi, P. Arduino, L. Margolis, J. Brattey, S. Webb, S. D’Amelio, P. Orecchia, and L. Bullini. 1997. Genetic and ecological data on the Anisakis simplex complex, with evidence for a new species (Nematoda, Ascaridoidea, Anisakidae). Journal of Parasitology 83: 401-416.

, L. Paggi, G. Nascetti, E. Abollo, S. C. Webb, S. Pascual, R. CiANChI, AND L. BUllini. 2001. Genetic divergence and reproductive isolation between Anisakis brevispiculata and Anisakis physeteris (Nematoda: Anisakidae). International Journal for Parasitology 31: 9-14.

, H. Ishikura, K. Kikuchi, N. SAto, R. CianCHI, AND L. Bullini. 1998. Allozyme and morphological identification of Anisakis, Contracaecum and Pseudoterranova from Japanese waters (Nematoda, Ascaridoidea). Systematic Parasitology 40: $81-92$.

C. P. Santos, G. Costa, A. P. Di BeneditTo,

R. Ramos, M. Argyrou, R. Cianchi, And L. Bullini. 2002. Genetic markers in the study of Anisakis typica (Diesing, 1860): Larval identification and genetic relationships with other species of Anisakis Dujardin, 1845 (Nematoda: Anisakidae). Systematic Parasitology 51: 159-170.

Mitchell, A., C. Mitter, And J. C. Regier. 2000. More taxa or more characters revisited: Combining data from nuclear protein-encoding genes for phylogenetic analyses of Noctuoidea (Insecta: Lepidoptera). Systematic Biology 49: 202-224.

Moneo, I., M. L. Caballero, F. Gomez, E. Ortega, and M. J. Alonso. 2000. Isolation and characterization of a major allergen from the fish parasite Anisakis simplex. Journal of Allergy and Clinical Immunology 106: 177-182.

NADler, S. A. 1995. Advantages and disadvantages of molecular phylogenetics: A case study of ascaridoid nematodes. Journal of Nematology 27: 423-432.

2002. Species delimitation and nematode biodiversity: Phylogenies rule. Nematology 4: 615-625.

. 2005. Speciation and species delimitation. In Marine parasites, K. Rohde (ed.). CSIRO Publishing, Collingwood, Australia, p. 339-345.

, R. A. Carreno, B. J. Adams, H. Kinde, J. G. Baldwin, And M. Mundo-OCAMPO. 2003. Molecular phylogenetics and diagnosis of soil and clinical isolates of Halicephalobus gingivalis (Nematoda: Cephalobina: Panagrolaimoidea), an opportunistic pathogen of horses. International Journal for Parasitology 33: 1115-1125.

, S. D'Amelio, H. P. Fagerholm, B. Berland, and L. Paggi 2000. Phylogenetic relationships among species of Contracaecum Railliet \& Henry, 1912 and Phocascaris Host, 1932 (Nematoda: Ascaridoidea) based on nuclear rDNA sequence data. Parasitology 121: $455-463$.
, AND D. S. S. HudsPETH. 1998. Ribosomal DNA and phylogeny of the Ascaridoidea (Nemata: Secernentea): Implications for morphological evolution and classification. Molecular Phylogenetics and Evolution 10: 221-236.

, AND - 2000. Phylogeny of the Ascaridoidea (Nematoda: Ascaridida) based on three genes and morphology: Hypotheses of structural and sequence evolution. Journal of Parasitology 86: 380393.

Nascetti, G., R. Cianchi, S. Mattiucci, S. D’Amelio, P. Orecchia, L. Paggi, J. Brattey, B. Berland, J. W. Smith, and L. Bullini. 1993. Three sibling species within Contracaecum osculatum (Nematoda, Ascaridida, Ascaridoidea) from the Atlantic Arctic-boreal region: Reproductive isolation and host preferences. International Journal for Parasitology 23: 105-120.

, L. Paggi, P. Orecchia, J. W. Smith, S. Mattiucci, and L. Bullini. 1986. Electrophoretic studies on the Anisakis simplex complex (Ascaridida: Anisakidae) from the Mediterranean and North-East Atlantic. International Journal for Parasitology 16: 633640.

Orecchia, P., L. Paggi, S. Mattiucci, J. W. Smith, G. Nascetti, and L. Bullini. 1986. Electrophoretic identification of larvae and adults of Anisakis (Ascaridida: Anisakidae). Journal of Helminthology 60: 331-339.

PAGgi, L., AND L. Bullini. 1994. Molecular taxonomy in anisakids. Bulletin of the Scandinavian Society of Parasitology 4: 25-39.

, S. Mattiucci, D. I. Gibson, B. Berland, G. Nascetti, R. CianCHI, AND L. Bullini. 2000. Pseudoterranova decipiens species A and B (Nematoda, Ascaridoidea): Nomenclatural designation, morphological diagnostic characters and genetic markers. Systematic Parasitology 45: 185-197.

- - H. Ishikura, K. Kikuchi, N. SAto, G. Nascetti, R. Cianchi, AND L. Bullini. 1998. Molecular genetics in anisakid nematodes from the Pacific Boreal region. In Host response to international parasitic zoonoses, H. Ishikura (ed.). Springer-Verlag, Tokyo, Japan, p. 83-107.

, G. Nascetti, R. Cianchi, P. Orecchia, S. Mattiucci, S. D’Amelio, B. Berland, J. Brattey, J. W. Smith, and L. Bullini. 1991. Genetic evidence for three species within Pseudoterranova decipiens (Nematoda, Ascaridida, Ascaridoidea) in the North Atlantic and Norwegian and Barents Seas. International Journal for Parasitology 21: 195-212.

, - S. C. Webb, S. Mattiucci, R. Cianchi, and L. BulLINI. 1998. A new species of Anisakis Dujardin, 1845 (Nematoda, Anisakidae) from beaked whales (Ziphiidae): Allozyme and morphological evidence. Systematic Parasitology 40: 161-174.

PosadA, D., And K. A. CRAndall. 1998. MODELTEST: Testing the model of DNA substitution. Bioinformatics 14: 817-818.

Rohlwing, T., H. W. Palm, and H. Rosenthal. 1998. Parasitation with Pseudoterranova decipiens (Nematoda) influences the survival rate of the European smelt Osmerus eperlanus retained by a screen wall of a nuclear power plant. Diseases of Aquatic Organisms 32: 233236.

Sakanari, J. A., And J. H. McKerrow. 1989. Anisakiasis. Clinical Microbiology Reviews 2: 278-284.

SHIH, H.-H. 2004. Parasitic helminth fauna of the cutlass fish, Trichiurus lepturus L., and the differentiation of four anisakid nematode thirdstage larvae by nuclear ribosomal DNA sequences. Parasitology Research 93: 188-195.

Spraker, T. R., E. T. Lyons, S. C. Tolliver, and H. D. Bair. 2003. Ascaridoid nematodes and associated lesions in stomachs of subadult male northern fur seals (Callorhinus ursinus) on St. Paul Island, Alaska: (1987-1999). Journal of Veterinary Diagnostic Investigation 15: 432-437.

SwOFFORD, D. L. 1998. PAUP*: Phylogenetic anaylsis using parsimony (*and other methods). Sinauer Associates, Sunderland, Massachusetts.

Zhu, X., R. B. Gasser, and N. B. Chilton. 1998. Differences in the 5.8S rDNA sequences among ascarid nematodes. International Journal for Parasitology 28: 617-622.

, M. Podolska, And N. B. Chilton. 1998. Characterisation of anisakid nematodes with zoonotic potential by nuclear ribosomal DNA sequences. International Journal for Parasitology 28: 1911-1921. 
— trophoretic detection of population variation within Contracaecum ogmorhini (Nematoda: Ascaridoidea : Anisakidae). Electrophoresis 22: $1930-1934$

- L. Paggi, And R. B. Gasser. 2000. Assessing sequence variation in the internal transcribed spacers of ribosomal DNA within and among members of the Contracaecum osculatum complex (Nematoda: Ascaridoidea: Anisakidae). Parasitology Research 86: 677-683.

- , H. W. Palm, L. Paggi, M. George-Nascimento, And R. B. GASSER. 2002. SSCP-based identification of members within the Pseudoterranova decipiens complex (Nematoda: Ascaridoidea: Anisakidae) using genetic markers in the internal transcribed spacers of ribosomal DNA. Parasitology 124: 615-623. 


\section{ERRATUM. .}

We have printed the first page (of 3 pages) of Figure 4 from Nadler et al., 2005, volume 91: 1413-1429. Unfortunately, in the original paper, the first full page of Figure 4 was missing, whereas the second page of the figure was reproduced twice.
A. simplex s. str.
A. simplex $\mathrm{C}$
A. pegreffii
A. ziphidarum
A. physeteris
A. brevispiculata
A. typica
Anisakis sp. PRP C140 Anisakis sp. HP C141
Anisakis sp. NES 2013
A. simplex s. str.
A. simplex $\mathrm{C}$
A. pegreffii
A. ziphidarum
A. physeteris
A. brevispiculata
A. typica
Anisakis sp. PRP C140 Anisakis sp. HP C141
Anisakis sp. NES 2013
A. simplex s. str.
A. simplex $\mathrm{C}$
A. pegreffii
A. ziphidarum
A. physeteris
A. brevispiculata
A. typica

Anisakis sp. PRP C140 Anisakis sp. HP C141 Anisakis sp. NES 2013

A. simplex s. str.

A. simplex $\mathrm{C}$

A. pegreffii

A. ziphidarum

A. physeteris

A. brevispiculata

A. typica

Anisakis sp. PRP C140

Anisakis sp. HP C141

Anisakis sp. NES 2013
A. simplex s. str.
A. simplex $\mathrm{C}$
A. pegreffii
A. ziphidarum
A. physeteris
A. brevispiculata
A. typica
Anisakis sp. PRP C140
Anisakis sp. HP C141
Anisakis sp. NES 2013

$10 \quad 20 \quad 30 \quad 40 \quad 50 \quad 60$

ATCCAAAACG AACGAAAAAG TCTCCCAACG TGCATACCTT CCATTTGCAT GTTGTTGTGA

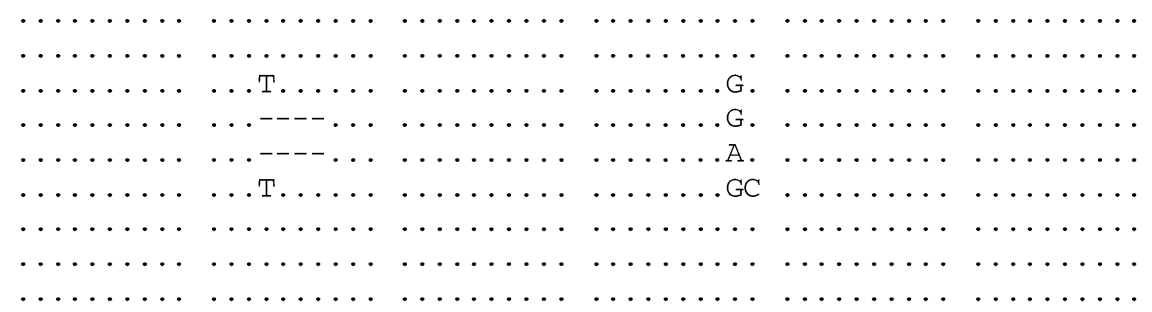

$\begin{array}{llllll}70 & 80 & 90 & 100 & 110 & 120\end{array}$

GCCACATGGA AACTCGTACA CAC-----GT GGTGGCAGCC GTCTGCTGTG CTTTTTTTAG

\begin{tabular}{|c|c|c|c|c|c|}
\hline & $\cdots$ & $\ldots----\ldots$ & $\ldots \ldots \ldots$ & $\ldots \ldots \ldots$ & $\ldots$ \\
\hline .G... & $\ldots \ldots \ldots$ & $\ldots \mathrm{T}-----\ldots$ & $\ldots \ldots \ldots$ & $\ldots \ldots \ldots$ & .....GT. \\
\hline ......... & $\ldots$. A... & $\ldots \mathrm{T}-----\ldots$ & $\ldots \ldots \ldots$ & $\ldots \ldots \ldots$ & ......GT. \\
\hline$\ldots G \ldots \ldots$ & $\ldots$. A. . & $\ldots \mathrm{T}-----\ldots$ & $\ldots \ldots \ldots$ & $\ldots \ldots \ldots$ & ...A. GT. \\
\hline ...G.C... & & .GTTTGTG. . & ...АТ... & & .G. .CG..G. \\
\hline$\cdots \cdots \cdots$ & $\ldots \ldots \ldots$ & $\ldots-----\ldots$ & $\cdots \cdots \cdots$ & $\cdots \cdots \cdots$ & $\ldots \ldots \ldots$ \\
\hline$\ldots \ldots \ldots$ & $\cdots \cdots \cdots \cdots$ & $\ldots-----$ & $\cdots \cdots \cdots \cdots$ & $\cdots \cdots \cdots \cdots$ & $\cdots \cdots \cdots \cdots$ \\
\hline
\end{tabular}

$130 \quad 140 \quad 150 \quad 160 \quad 170 \quad 180$

GCAGACAATG GCTTACGAGT GGCC-GTG-T GCTTGTTGAA CAACGGTGAC CAATTTGGC-

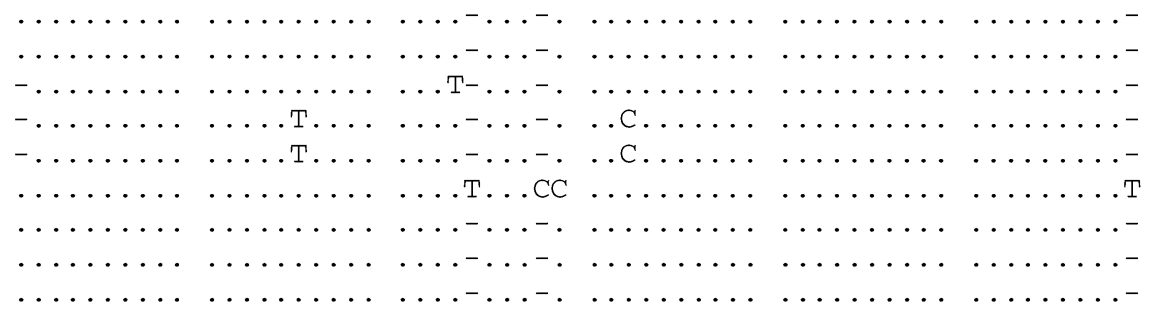

$\begin{array}{lllllr}190 & 200 & 210 & 220 & 230 & 240\end{array}$

GTCTACGCCG TATCTAGCTT CTGCCTGGAC CGTCAGTTGC GATGAAAGAT GCGGAGAAAG

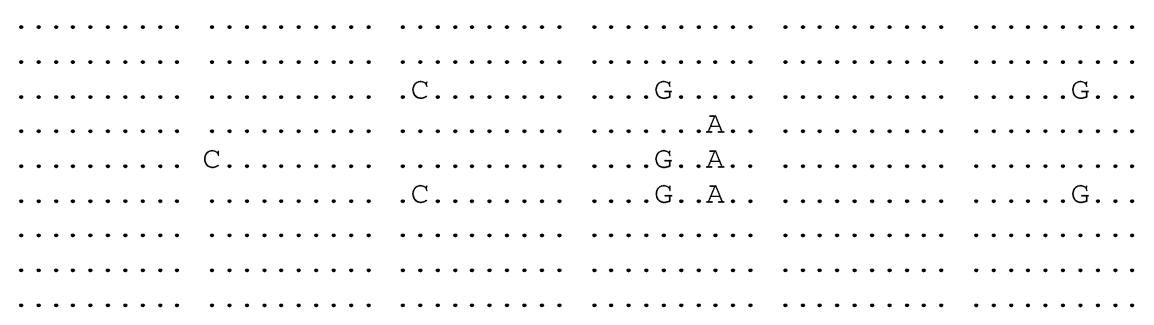

$250 \quad 260 \quad 270 \quad 280 \quad 300$

TTCCTTTGTT TTGGCTGCTA ATCATCATTG ATGAGCAGTA GCTTAAGGCA GAGTTGAGCA

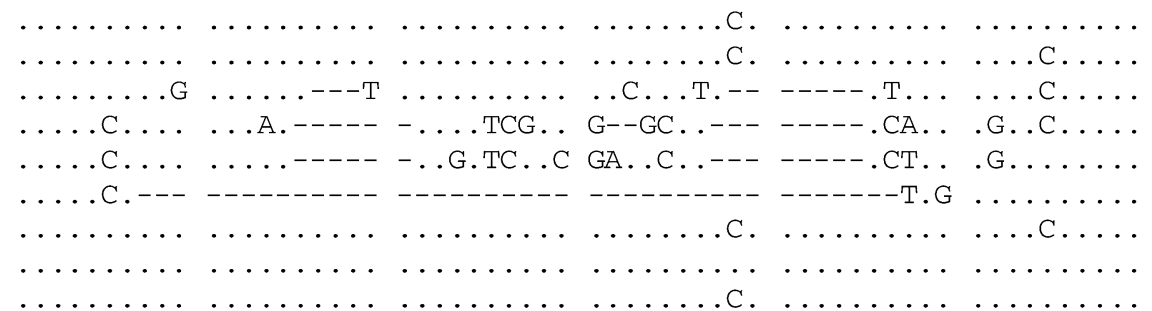

FIGURE 4. Alignment of ITS-1 positions 1-300 for sequences of Anisakis taxa. One representative of each unique sequence was included for comparison. Dots indicate identity with the first sequence and dashes are inferred insertion-deletion events. Positions 301-395 of ITS-1 and sequences for ITS-2 (positions 396-765) are correct as found in the original paper. 
Published in the Journal of Parasitology (2007) 93(2): 444. DOI: 10.1645/0022-3395(2007)93[444:E]2.0.CO;2. Copyright 2007, American Society of Parasitologists. Used by permission.

ERRATUM... We have printed the first page (of 3 pages) of Figure 4 from Nadler et al., 2005, volume 91: 1413-1429. Unfortunately, in the original paper, the first full page of Figure 4 was missing, whereas the second page of the figure was reproduced twice.

A. simplex s. str.
A. simplex C
A. pegreffii
A. ziphidarum
A. physeteris
A. brevispiculata
A. typica
Anisakis sp. PRP C140
Anisakis sp. HP C141
Anisakis sp. NES 2013

\begin{tabular}{|c|c|c|c|c|c|}
\hline 0 & 20 & 30 & 40 & 0 & \\
\hline & AG : & $\mathrm{CC}$ & TT & $\mathrm{C}$ & \\
\hline$\cdots$ & $\ldots \ldots \ldots$ & $\ldots \ldots \ldots$ & $\ldots \ldots \ldots$ & $\ldots \ldots \ldots$ & $\ldots \ldots$ \\
\hline$\cdots$ & $\ldots \ldots \ldots$ & $\ldots \ldots \ldots$ & $\ldots \ldots \ldots$ & $\ldots \ldots \ldots$ & $\ldots \ldots \ldots$ \\
\hline & $\ldots$ T..... & & $\ldots \ldots \ldots$ G. & $\ldots \ldots \ldots$ & $\ldots \ldots \ldots$ \\
\hline & $\ldots, \cdots$ & & $\ldots G$. & $\cdots$ & \\
\hline & $\ldots+-\cdots$ & & A. & $\ldots$ & \\
\hline & & & $\ldots G C$ & $\cdots$ & \\
\hline & $\cdots \cdots$ & $\ldots \ldots$ & $\cdots \cdots$ & $\cdots$ & \\
\hline & & & & & \\
\hline & & $\cdots$ & 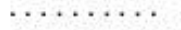 & & \\
\hline
\end{tabular}

A. simplex s. str.

80

100

110 120

A. simplex C

A. pegreffii

A. ziphidarum

A. physeteris

A. brevispiculata

A. typica

Anisakis sp. PRP C140

Anisakis sp. HP C141

Anisakis sp. NES 2013

GCCACATGGA AACTCGTACA CAC----GT GGTGGCAGCC GTCTGCTGTG CTTPTTTTAG

$\ldots \ldots \ldots \ldots, \ldots \ldots \ldots \ldots, \ldots \ldots \ldots \ldots \ldots \ldots \ldots \ldots \ldots \ldots$

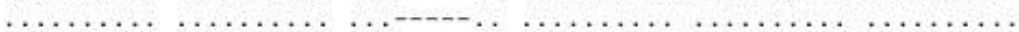

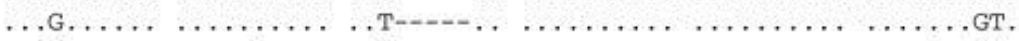

$\ldots$ G. . . . . . . . . .

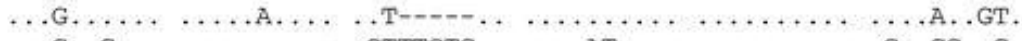

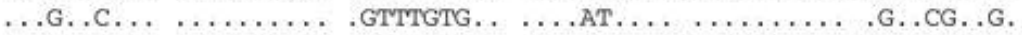

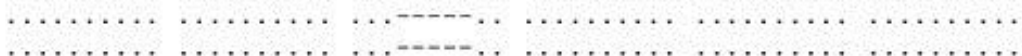

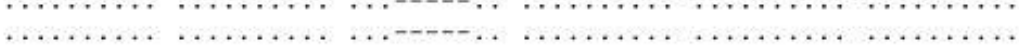

A. simplex s. str.

$\begin{array}{llllll}130 & 140 & 150 & 160 & 170 & 180\end{array}$

A. simplex $\mathrm{C}$

A. pegreffii

A. ziphidarum

A. physeteris

A. brevispiculata

A. typica

Anisakis sp. PRP C 140

Anisakis sp. HP C141

Anisakis sp. NES 2013

GCAGACAATG GCTTACGAGT GGCC-GTG-T GCTTGTTGAA CAACGGTGAC CAATTTGGC-

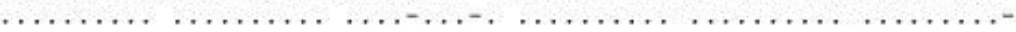

$\ldots \ldots \ldots \ldots, \ldots \ldots \ldots \ldots, \ldots \ldots-\ldots-. \ldots \ldots \ldots \ldots \ldots \ldots \ldots \ldots \ldots \ldots \ldots-$

$-\ldots \ldots \ldots \ldots \ldots \ldots \ldots \ldots \ldots \ldots \ldots \ldots \ldots \ldots \ldots \ldots \ldots \ldots \ldots \ldots$

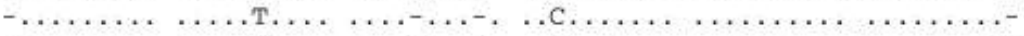

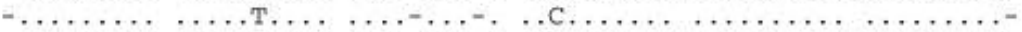

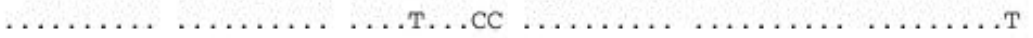

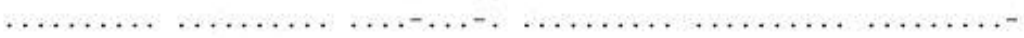

$\ldots \ldots \ldots \ldots \ldots \ldots \ldots \ldots \ldots \ldots \ldots \ldots \ldots \ldots \ldots \ldots \ldots \ldots$

$\ldots \ldots \ldots \ldots, \ldots \ldots \ldots \ldots, \ldots, \ldots,-\ldots \ldots \ldots \ldots \ldots \ldots \ldots \ldots \ldots$

A. simplex s. str.

$\begin{array}{cccccc}190 & 200 & 210 & 220 & 230 & 240 \\ \text { GTCTACGCCG TATCTAGCTT CTGCCTGGAC } & \text { CGTCAGTTGC } & \text { GATGAAAGAT } & \text { GCGGAGAAAG }\end{array}$

A. simplex C

A. pegreffii

A. ziphidarum

A. physeteris

A. brevispiculata

A. typica

Anisakis sp. PRP C140

Anisakis sp. HP C141

Anisakis sp. NES 2013

A. simplex s. str.

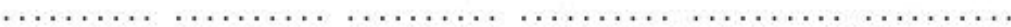

$\ldots \ldots \ldots \ldots, \ldots \ldots \ldots \ldots, \ldots \ldots \ldots \ldots, \ldots \ldots \ldots \ldots \ldots, \ldots \ldots \ldots \ldots, \ldots \ldots \ldots \ldots$

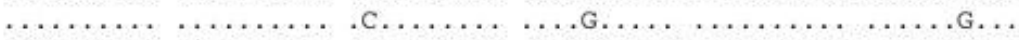

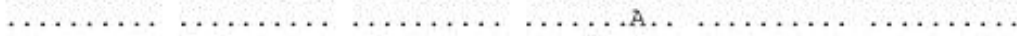

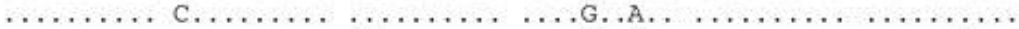

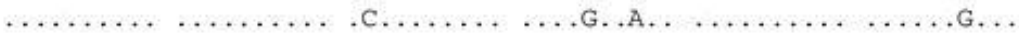

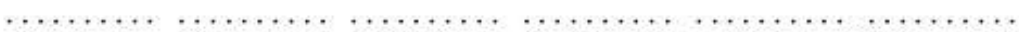

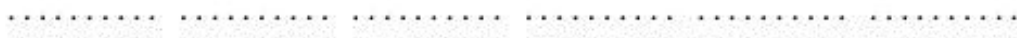

$\ldots \ldots \ldots, \ldots \ldots, \ldots, \ldots \ldots \ldots, \ldots \ldots \ldots, \ldots \ldots \ldots, \ldots \ldots \ldots$

$\begin{array}{lllll}250 & 260 & 270 & 280 & 290\end{array}$

A. simplex $\mathrm{C}$

A. pegreffii

A. ziphidarum

A. physeteris

A. brevispiculata

A. typica

Anisakis sp. PRP C140

Anisakis sp. HP C141

Anisakis sp. NES 2013

TTCCTTTGTT TTGGCTGCTA ATCATCATTG ATGAGCAGTA GCTTAAGGCA GAGTTGAGCA

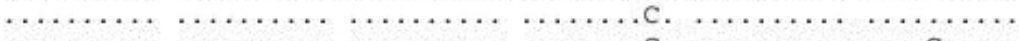

$\ldots \ldots \ldots, \ldots \ldots \ldots \ldots, \ldots \ldots \ldots, \ldots \ldots \ldots, \ldots \ldots \ldots \ldots, \ldots, \ldots \ldots$

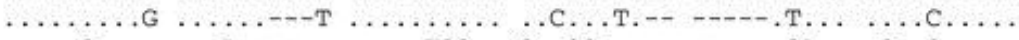

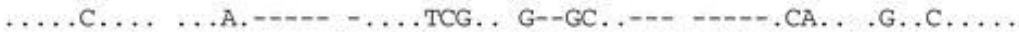

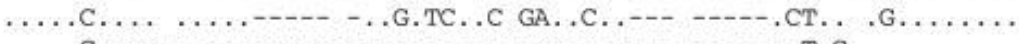

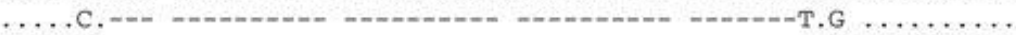

$\ldots \ldots \ldots \ldots, \ldots \ldots \ldots, \ldots \ldots \ldots, \ldots \ldots \ldots, \ldots, \ldots \ldots \ldots, \ldots, \ldots \ldots$

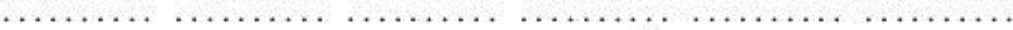

$\ldots \ldots \ldots \ldots, \ldots \ldots \ldots \ldots \ldots \ldots \ldots \ldots \ldots \ldots \ldots \ldots \ldots \ldots \ldots$

Figure 4. Alignment of ITS-1 positions 1-300 for sequences of Anisakis taxa. One representative of each unique sequence was included for comparison. Dots indicate identity with the first sequence and dashes are inferred insertion-deletion events. Positions 301-395 of ITS-1 and sequences for ITS-2 (positions 396-765) are correct as found in the original paper. 